Submitted for review to the International Journal of Fatigue

\title{
Influence of Coarsened and Rafted Microstructures on the Thermomechanical Fatigue of a Ni-base Superalloy
}

\author{
by \\ M. M. Kirka ${ }^{1, a}$, K. A. Brindley ${ }^{1}$, R. W. Neu ${ }^{1,2 *}$, S. D. Antolovich ${ }^{1,2}$, S. R. Shinde ${ }^{3}$, P. W. \\ Gravett $^{3}$, \\ ${ }^{1}$ The George W. Woodruff School of Mechanical Engineering \\ ${ }^{2}$ School of Materials Science and Engineering \\ Georgia Institute of Technology, Atlanta, GA, 30332 \\ ${ }^{3}$ Siemens Energy Inc., Orlando, FL 32826 \\ ${ }^{a}$ Current address: Oak Ridge National Laboratory, One Bethel Valley Road, Oak Ridge, \\ TN 37831, USA. \\ *corresponding author: email: rick.neu@gatech.edu, tel: 1-404-894-3074
}

\begin{abstract}
The aging of the microstructure of Ni-base superalloys during service is primarily characterized by coarsening and rafting of the $\gamma^{\prime}$ precipitates. The influence of these different aged microstructures on thermomechanical fatigue (TMF) under either continuously cycled (CC) and creep-fatigue (CF) was investigated. Three different aged microstructures, generated through accelerated aging and pre-creep treatments, were studied: stress-free coarsened $\gamma^{\prime}$, rafted with orientation perpendicular to loading direction (N-raft), and rafted with orientation parallel to loading direction (P-raft). Under most conditions, the aged microstructures were less resistant to TMF than the virgin microstructure; however, there were exceptions. Both stress-free coarsened and N-raft microstructures resulted in a reduction in TMF life under both $\mathrm{CC}$ and $\mathrm{CF}$ conditions in comparison to the virgin material. P-raft microstructure also resulted in reduction in TMF life under CC conditions; however, an increase in life over that of the virgin material was observed under CF conditions. These differences are discussed and hypothesized to be related to the interactions of the dislocations in the $\gamma$ channels with $\gamma^{\prime}$ precipitates.
\end{abstract}

Keywords: Thermomechanical fatigue, Nickel-base superalloy, strain-life, rafting, aging 


\section{Introduction}

The high temperature strength of Ni-base superalloys is primarily dependent on the interaction of dislocations with the intermetallic $\gamma^{\prime}$ precipitates. Consequently, the mechanical behavior of Ni-base superalloys is highly sensitive to not only the volume fraction of $\gamma^{\prime}$ precipitates, which is near $0.70 \%$ in modern superalloys for these applications, but also to the morphology of the precipitates [1-3]. Aging during service causes these $\gamma^{\prime}$ precipitates to coarsen and change morphology, both of which need to be considered in fatigue and creep analyses.

Aging involves a combination of self-similar and directional coarsening, the latter often termed "rafting". The most discernible changes are observed in the dendritic regions of the microstructure. Self-similar coarsening occurs under stress-free conditions when exposed to temperatures greater than $700^{\circ} \mathrm{C}$. In the presence of a stress and temperatures in typically in excess of $850^{\circ} \mathrm{C}[4], \gamma^{\prime}$ precipitates directionally coarsen forming a rafted structure. Under stress-free conditions the $\gamma^{\prime}$ coarsen according to diffusion-controlled Ostwald ripening kinetics, whereas rafting is the result of Ostwald ripening and directional coalescence kinetics which occur simultaneously $[5,6]$.

The direction the $\gamma^{\prime}$ rafts form depends on the relative lattice mismatch of the $\gamma$ and $\gamma^{\prime}$ phases $\delta$, where

$$
\delta=2 \frac{\left(a_{\gamma^{\prime}}-a_{\gamma}\right)}{\left(a_{\gamma^{\prime}}+a_{\gamma}\right)}=\frac{\delta a}{\bar{a}}
$$

$a_{\gamma}$ and $a_{\gamma^{\prime}}$ are the lattice constants of the $\gamma$ matrix and the $\gamma^{\prime}$ precipitates, respectively, and the sign of the applied stress, which influences both the relative internal stresses in the $\gamma$ and $\gamma^{\prime}$ phases and the heterogeneity of the dislocations absorbed at the $\gamma / \gamma^{\prime}$ interfaces impacting the directionality of diffusion $[3,7,8]$. As is the case of most modern Ni-base superalloys used in the hot section of gas turbines, the lattice misfit of the alloy is designed to be negative over the entire operational temperature range such that when placed under a tensile load at temperature, the rafts will align normal to the stress axis (N-rafts) and when placed under a compressive stress, the rafts will align parallel to the applied load (P-rafts) [9].

The influence of $\gamma^{\prime}$ aging has been studied to understand its impact on creep rupture strength and creep rates of Ni-base superalloys $[10,11]$. In most cases, an aged microstructure results in an increase in creep rate. However, pre-rafting in compression to generate P-raft microstructures has been shown to reduce the tensile creep rate [10]. Relatively few studies have been conducted to understand their influence on the fatigue behavior of Ni-base superalloys. Antolovich et al. [12] studied the effects of artificially stress-free coarsened $\gamma^{\prime}$ precipitates on the isothermal low cycle fatigue (LCF) behavior 

life. Ott and Mughrabi [13] and Gordon et al. [14] studied the effects of both N-rafts and P-rafts on the isothermal LCF performance on several Ni-base superalloys in comparison to virgin material in the standard heat treated state. Their studies indicated that N-raft microstructure results in a decrease in life, while the P-raft microstructure may be beneficial in increasing the life under certain strain-temperature cycles $[13,14]$. In particular, under out-of-phase (OP) thermomechanical fatigue (TMF) conditions, an N-raft microstructure generated by tensile pre-creep treatment was found to reduce life by a factor of 2.5x [15]. However, results were mixed with P-raft microstructures. While P-raft microstructures also resulted in a reduced life under an OP TMF cycle, a counter-clockwise-diamond (CCD) cycle resulted in a $2 \mathrm{x}$ increase in life $[13,16,17]$.

A rafted microstructure is often observed at the end of creep and TMF tests. Under creep conditions, rafting is not typically observed to occur at temperatures below $850^{\circ} \mathrm{C}$, but at $950^{\circ} \mathrm{C}$, the formation of rafts is generally accompanied by an increase in the creep rate [10]. Rafting is often observed to occur in high temperature fatigue tests, particularly when dwells are included in the cycle. Arrell et al. [18] reported rafting under creep-fatigue (CF) TMF conditions on the single crystal (SX) alloy CMSX-4 and was used to explain the softening behavior the material exhibited under cyclic conditions. Further, Kupkovits and Neu [19] have observed rafting surrounding regions of cracking in notched specimens undergoing TMF.

It is unclear whether specific aged microstructures are beneficial or detrimental to the fatigue life of Ni-base superalloys [20]. Specifically, if an aged microstructure is beneficial, which type ( $\mathrm{N}$ - or P-rafts) is beneficial, and under what loading and temperature conditions is the microstructure beneficial? Further, Arrell et al. [18] noted that to avoid non-conservative estimations in service component designs, understanding of the effect of aged materials on the TMF life is required. To address these questions and concerns, this work systematically studies three distinctly different aged conditions and experimentally investigates how each of these aged microstructures influences TMF life.

\section{Experimental Procedure}

\subsection{Material}

The material investigated is a second-generation directionally-solidified (DS) Ni-base superalloy of chemical composition shown in Table 1 . The material was provided in the 
form of cast slabs having dimensions $127 \times 228 \times 25.4 \mathrm{~mm}$, and was given a proprietary two-step heat treatment representing that typically given to a blade component. The heat treatment promotes elemental homogenization and precipitation of the $\gamma^{\prime}$ precipitates. As a result of the heat treatment, the alloy is comprised of $65 \% \gamma^{\prime}$ by volume fraction, with the $\gamma^{\prime}$ being cubic in shape and having an average side length of $0.7 \mu \mathrm{m}$ and the $\gamma$ channels having an average width of $0.17 \mu \mathrm{m}$ in the dendritic core (Figure 1a). Within the $\gamma$ channels, secondary $\gamma^{\prime}$ were present with size of $70 \mathrm{~nm}$. The average diameter of one of the columnar grains is $2 \mathrm{~mm}$, with the primary dendrites spaced $500 \mu \mathrm{m}$ apart and the secondary dendrite arm spacing ranging from 100 to $200 \mu \mathrm{m}$. In all cases, the longitudinal grains were within the allowed $+/-7.5^{\circ}$ misoreintation relative to the growth direction [4]. Intermittent script grain boundary MC type carbides and blocky type $M_{23} C_{6}$ carbides were present within the interdendiritc regions. The carbides range in size from a few microns to $25 \mu \mathrm{m}$. Over the temperature range of interest the alloy exhibits a negative lattice misfit as determined through JMatPro (Sente Software Ltd., Surrey, United Kingdom).

Table 1: Nominal chemical composition of the DS Ni-base superalloy used in this work given as weight percent [21].

\begin{tabular}{cccccccccccc}
\hline Cr & Co & Mo & W & Al & Ti & Ta & Hf & C & B & Zr & Ni \\
\hline 8.1 & 9.2 & 0.5 & 9.5 & 5.6 & 0.7 & 3.2 & 1.4 & 0.07 & 0.015 & 0.01 & Bal
\end{tabular}

\section{$2.2 \quad$ Accelerated Aging}

Three distinct microstructures were generated through an accelerated aging procedure: one stress-free coarsened, one N-raft, and one P-raft microstructure. To produce a stress-free coarsened microstructure representative of the aged self-similar primary $\gamma^{\prime}$ observed in service, the as-heat treated alloy was exposed to $1000^{\circ} \mathrm{C}$ in open air using a 3-zone electric-resistance tube furnace for a period of $720 \mathrm{hrs}$. As a result of the thermal exposure the $\gamma^{\prime}$ cuboids increased in size to a cube length of $0.9 \mu \mathrm{m}$ on average from the initial average cube length of $0.7 \mu \mathrm{m}$ (Figure 1b). Additionally, the $\gamma$ channels were observed to be devoid of secondary $\gamma^{\prime}$. This can be attributed to the Ostwald ripening process through which the larger precipitates coarsen at the expense of the smaller ones $[4,22]$

The N-raft $\gamma^{\prime}$ microstructure was generated through tensile pre-creeping material for a period of $300 \mathrm{hrs}$ at $950^{\circ} \mathrm{C}$ and a stress of $130 \mathrm{MPa}$. The resulting N-rafted 
microstructure is shown in Figure 1c. The tensile pre-creep resulted in a fully N-rafted structure, where the average width of the $\gamma$ channels perpendicular to the applied load was increased from $0.17 \mu \mathrm{m}$ to $0.30 \mu \mathrm{m}$ on average. The accumulated creep strain was measured to be $0.37 \%$. The P-raft microstructure was produced through a compressive pre-creep treatment of $-130 \mathrm{MPa}$ at $950^{\circ} \mathrm{C}$ for $300 \mathrm{hrs}$ using a compression creep frame [23]. As a result of the compressive pre-creep exposure, the material experienced a compressive creep strain of approximately $0.4 \%$, with the $\gamma$ channels parallel to the applied load increased to a width of $0.25 \mu \mathrm{m}$ on average as depicted in Figure 1d.
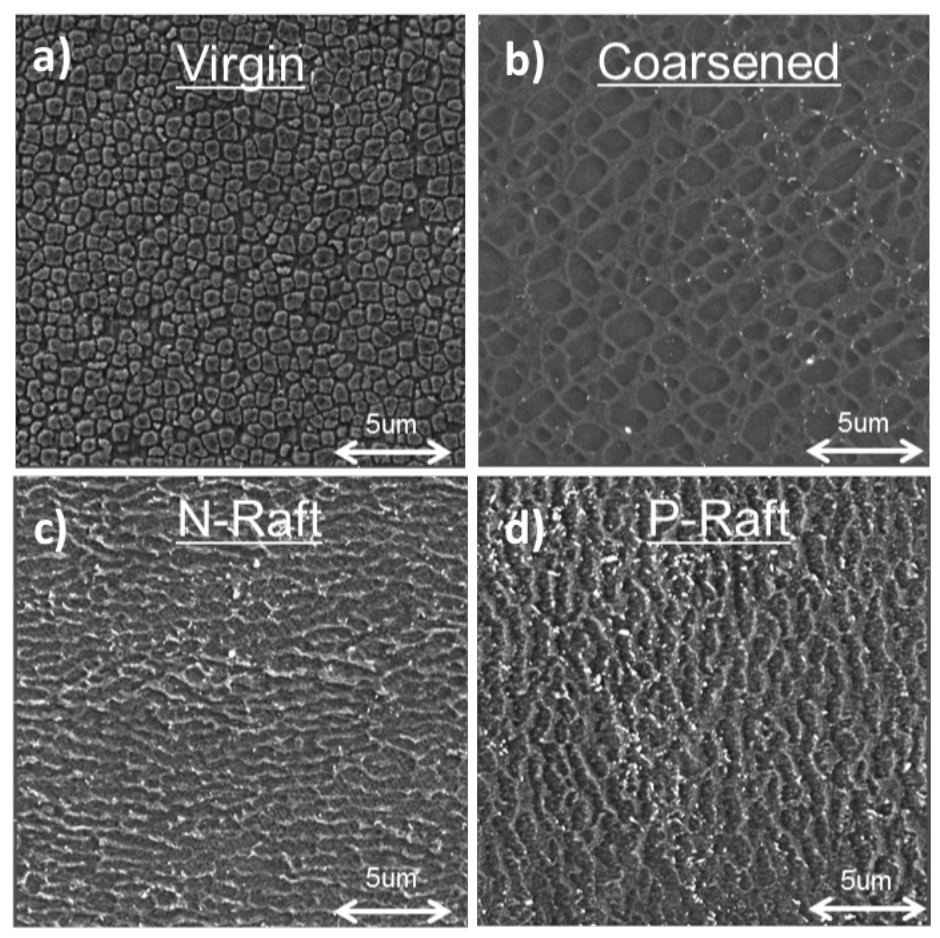

Figure 1: Comparison of microstructures: (a) virgin, (b) stress-free coarsened, (c) N-raft, and (d) P-raft.

\subsection{TMF Experiments}

TMF experiments were performed on cylindrical dog-bone specimens fabricated in accordance with ASTM E606-12 [24] having a gage section length of $13.2 \mathrm{~mm}$ (0.52 in) and diameter of $6.35 \mathrm{~mm}$ (0.25 in) shown in Figure 2. The load axis of all the specimens was aligned with the solidification direction of the slabs, i.e. the longitudinal orientation. The TMF experiments were performed on MTS closed loop servohydraulic test systems equipped with MTS FlexTest 40 controllers. Induction heating (Ameritherm 
$2.0 \mathrm{~kW}$ capacity) was used to heat the specimens with temperature feedback from 26gage Type $\mathrm{K}$ thermocouple spot welded to the specimen gage section located as shown in Figure 2. The temperature gradient over the gage section was minimized by optimization of the induction coil configuration to be within the requirements mandated by ASTM E2368-10 [25].

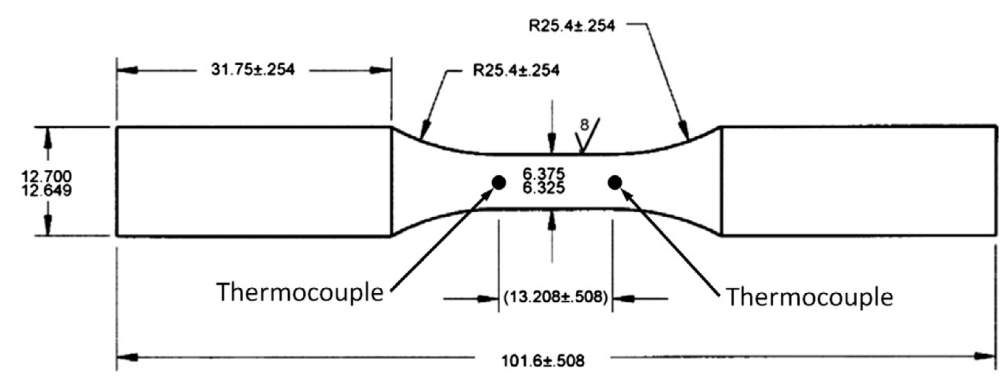

Figure 2: Cylindrical specimen with dimensions in $\mathrm{mm}$.

Total strain, $\epsilon_{t o t}=\epsilon_{m e c h}+\epsilon_{t h}$, was measured over the gage length with a $12.7 \mathrm{~mm}$ MTS high temperature axial extensometer utilizing alumina rods. All experiments were conducted in mechanical strain control, where the mechanical strain was calculated through subtraction of the thermal strain from the total strain measured by the extensometer, $\epsilon_{m e c h}=\epsilon_{t o t}-\epsilon_{t h}$. The thermal strain was determined through a polynomial fit to free thermal expansion response measured before the start of each test.

In gas turbine components, the strain-temperature-time profile controls which aged microstructure is generated. Therefore, the TMF cycle conditions were targeted to be consistent with service conditions that may result in the particular aged microstructure. Further, all microstructures were tested under both continuously cycled (CC) and creep-fatigue ( $\mathrm{CF}$ ) conditions. The $\mathrm{CF}$ condition includes a 20 minute strain hold at the peak temperature of the cycle. The mechanical strain amplitude was chosen to target conditions where the macroscopic hysteresis response exhibited minimal cyclic inelastic strain. When known, scatter in life results is given, otherwise a value of $+/-10 \%$ is shown. 


\section{Results and Discussion}

\subsection{TMF of Stress-free Coarsened Microstructure}

To explore the influence of stress-free coarsened microstructure, the most relevant TMF conditions in the context of a service component are IP TMF with $R_{\epsilon}=0$, with peak temperatures of $750^{\circ} \mathrm{C}$. This condition is considered representative of material in regions surrounding internal cooling passages [26]. While material near the surfaces of the internal cooling cavities can reach temperatures well in excess of $750^{\circ} \mathrm{C}, 750$ $800^{\circ} \mathrm{C}$ is near the upper limit under which the application of stress and temperature are expected to result in a non-rafted microstructures $[9,27]$. At temperatures above $850^{\circ} \mathrm{C}$, the expectations is for the $\gamma^{\prime}$ cuboids to raft in presence of a stress. Therefore, the comparative study to explore the impact of TMF on stress-free coarsened $\gamma^{\prime}$ were conducted with a $T_{\max }$ of $750^{\circ} \mathrm{C}$.

The TMF life comparisons are shown in Figure 3. For both microstructures, life is reduced with a reduction in the $T_{\min }$ and further reduced with inclusion of a dwell [28]. When comparing the same test conditions, the stress-free coarsened microstructure under $500-750^{\circ} \mathrm{C}$ CC TMF resulted in a $85 \%$ life reduction, while the TMF cycle with the lower $T_{\min }, 100-750^{\circ} \mathrm{C}$, exhibited a $65 \%$ life reduction when compared to the virgin material responses. Similar decreases in life have been reported for Rene 80 in an overaged state when tested under isothermal LCF conditions [12]. With the application of strain hold of $20 \mathrm{~min}$. at the peak temperature, no discernible difference between the virgin and coarsened microstructure was observed. 


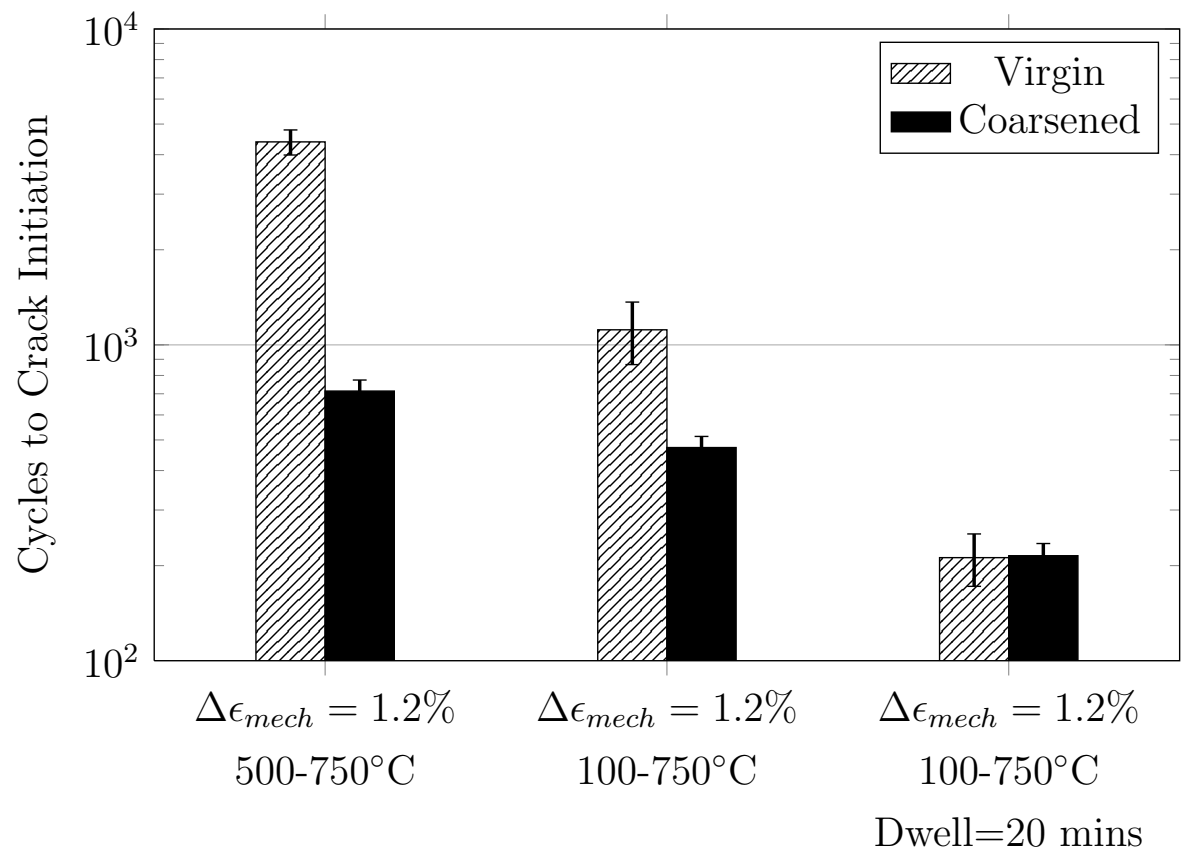

Figure 3: Comparison of lives between the stress-free coarsened and virgin microstructures under IP TMF loading conditions.

For the TMF conditions evaluated, the hysteresis response of the coarsened and virgin microstructures were similar in shape, shown in Figures 4a and 5a, though the mean stress remained higher for the coarsened microstructure, particularly for CC conditions. The mean stress was similar for both microstructures in the first cycle, it relaxed much more when starting with the virgin microstructure as shown in Figure 4b. This trend was observed to be repeatable for specimens taken from different slabs. However, in the case of the $\mathrm{CF}$ cycles, the mean stress occurring within the virgin material is observed to evolve towards and reach the stabilized mean stress of the coarsened microstructure (Figure 5b). 


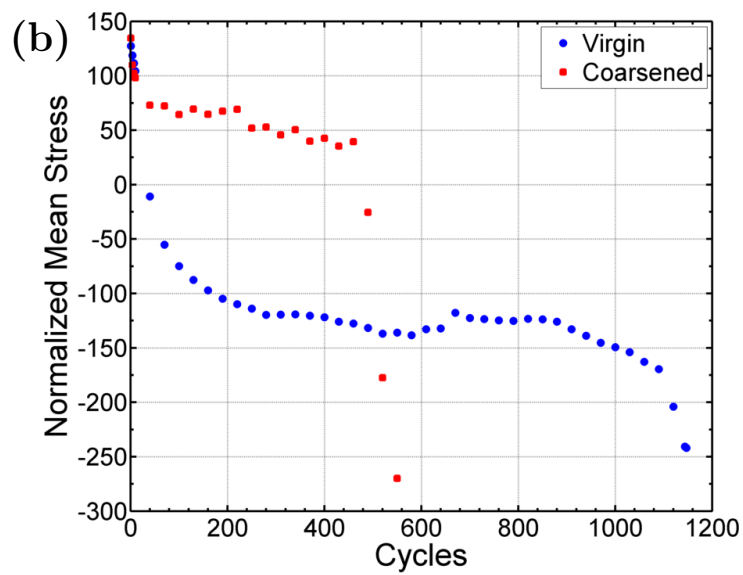

Figure 4: Comparison of stress-free coarsened microstructure to the virgin under CC IP TMF conditions $\left(\Delta T=100-750^{\circ} \mathrm{C}\right)$ showing (a) half-life hysteresis response and (b) mean stress evolution.
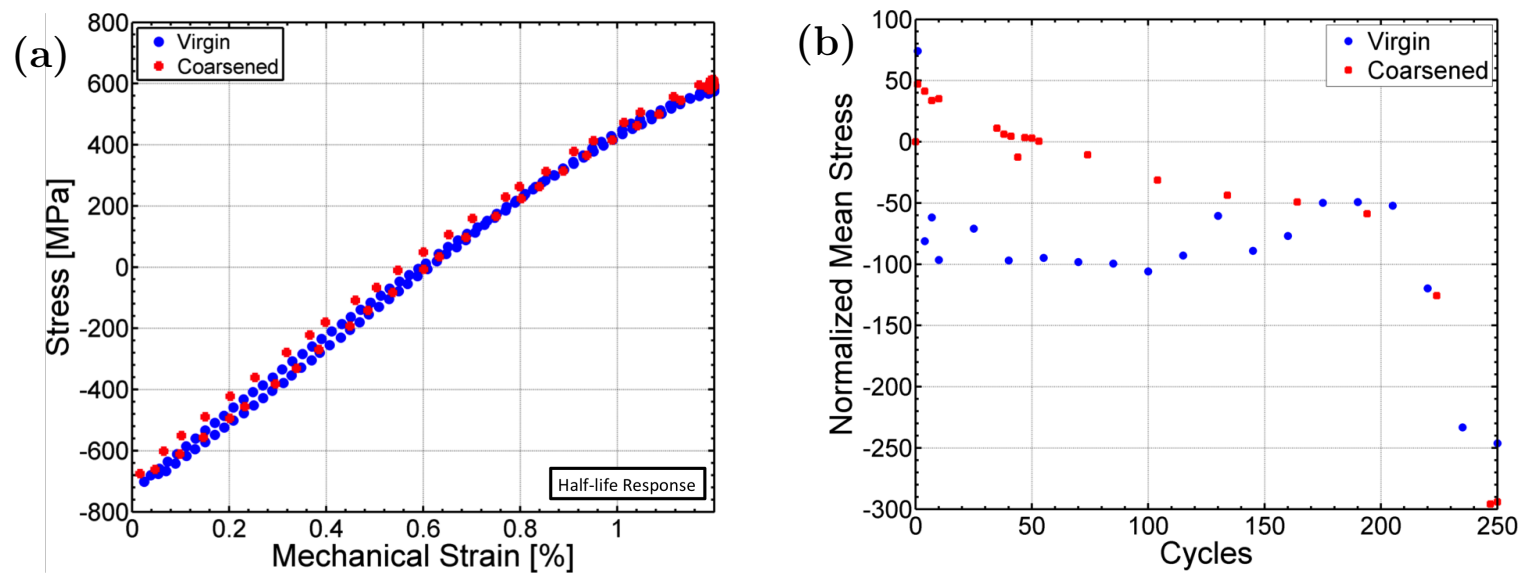

Figure 5: Comparison of stress-free coarsened microstructure to the virgin under CF IP TMF conditions $\left(\Delta T=100-750^{\circ} \mathrm{C}\right)$ showing (a) half-life hysteresis response and (b) mean stress evolution.

In all of these IP TMF experiments, multiple cracks nucleated near the interface of the matrix and carbides. These cracks propagated through the microstructure often through a linkage of these microcracks as shown in Figure 6. At the end of the test, the coarsened microstructure revealed significant carbide debonding similar to that observed in the virgin material. 


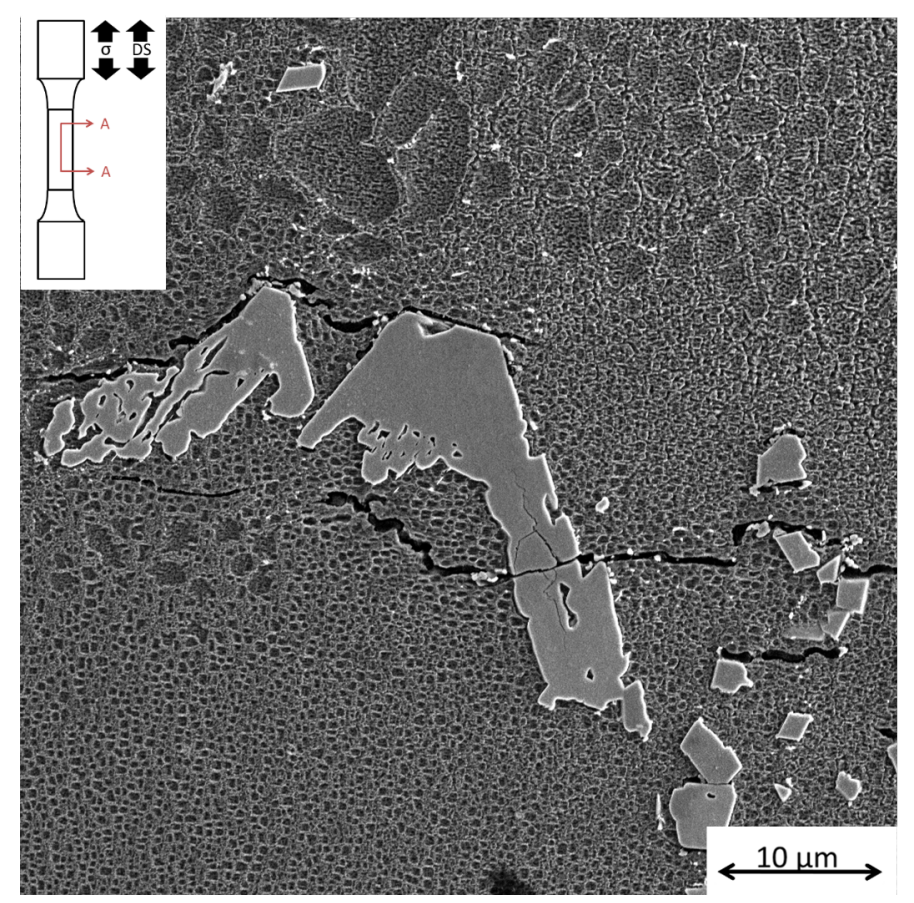

Figure 6: Debonded/cracked carbide located at a dendritic-interdendritic boundary within stress-free coarsened microstructure after exposure to IP TMF CC conditions $(\Delta T=500-$ $750^{\circ} \mathrm{C}$ and $\Delta \epsilon_{\text {mech }}=1.2 \%$ ).

In the CC TMF case, the higher mean stress sustained by the coarsened microstructure is likely associated with the lack of significant $\gamma-\gamma^{\prime}$ misfit stresses and hence no assistance to mean stress relaxation from these internal stresses. This higher mean stress coupled with the decrease in shear resistance of the overaged $\gamma^{\prime}$ microstructure [29] contribute to the large reduction in life in the stress-free coarsened condition. Under the CF conditions where there is no difference in life between the initial microstructures, the long dwell promotes stress relaxation in both the coarsened and virgin microstructures and consequently, the mean stress at half life are comparable. The accumulation of inelastic strain near the carbide interfaces is likely the controlling life limiting factor and not the differences in microstructure away from these interfaces. The aged condition of the microstructure controls how quickly the mean stress evolves and under IP TMF conditions where the tensile mean stress cannot relax as quickly, the life is reduced. 


\subsection{TMF of N-raft Microstructure}

In gas turbine components, N-rafts are naturally generated under IP TMF conditions in the case of a negative lattice mismatch alloy [4]. Consequently, the N-rafts form in regions surrounding the internal cooling passages [26]. Above temperatures of $900^{\circ} \mathrm{C}$ and moderate stresses, N-rafts are expected to rapidly develop as observed in the studies of $\gamma^{\prime}$ evolution kinetics [6]. Long term exposure $(10,000 \mathrm{hrs})$ at temperatures as low as $850^{\circ} \mathrm{C}$ and high stresses are capable of bringing about a rafted state $[6,30]$. Therefore, the comparison of microstructures is evaluated using IP TMF test conditions, and since IP TMF lives are highly sensitive to the maximum temperature, both $T_{\max }$ of $850^{\circ} \mathrm{C}$ and $950^{\circ} \mathrm{C}$ are considered with $R_{\epsilon}=0$.

The comparison of lives between N-raft and virgin microstructure for $T_{\max }$ of $850^{\circ} \mathrm{C}$ and $950^{\circ} \mathrm{C}$ are shown in Figure 7 and 8 , respectively. In all cases, the N-raft microstructure had either a shorter or similar life compared the virgin. The largest variation in lives between microstructures is the CC condition with strain amplitude on the verge to transition to macroscopic-apparent cyclic plastic strain (i.e., open hysteresis loop at half life), with the N-raft microstructure exhibiting a $50 \%$ reduction in life over the virgin microstructure for both $T_{\max }$ of 850 and $950^{\circ} \mathrm{C}$. These life reductions are consistent with reported results for other negative-misfit Ni-base superalloys given tensile pre-creep treatments that promote N-rafts $[13,15,16,18,31]$. When the cyclic plastic strain amplitude of the CC condition is sufficiently large, e.g., $\Delta \epsilon_{\text {mech }}=1.0 \%$, $100-950^{\circ} \mathrm{C}$, as seen in Figure 9, the impact of the prior microstructure appears to be negligible (Figure 8). Similar to the stress-free coarsened microstructure, adding a 20 min. dwell also tends to eliminate any influence of prior microstructure on IP TMF life. 


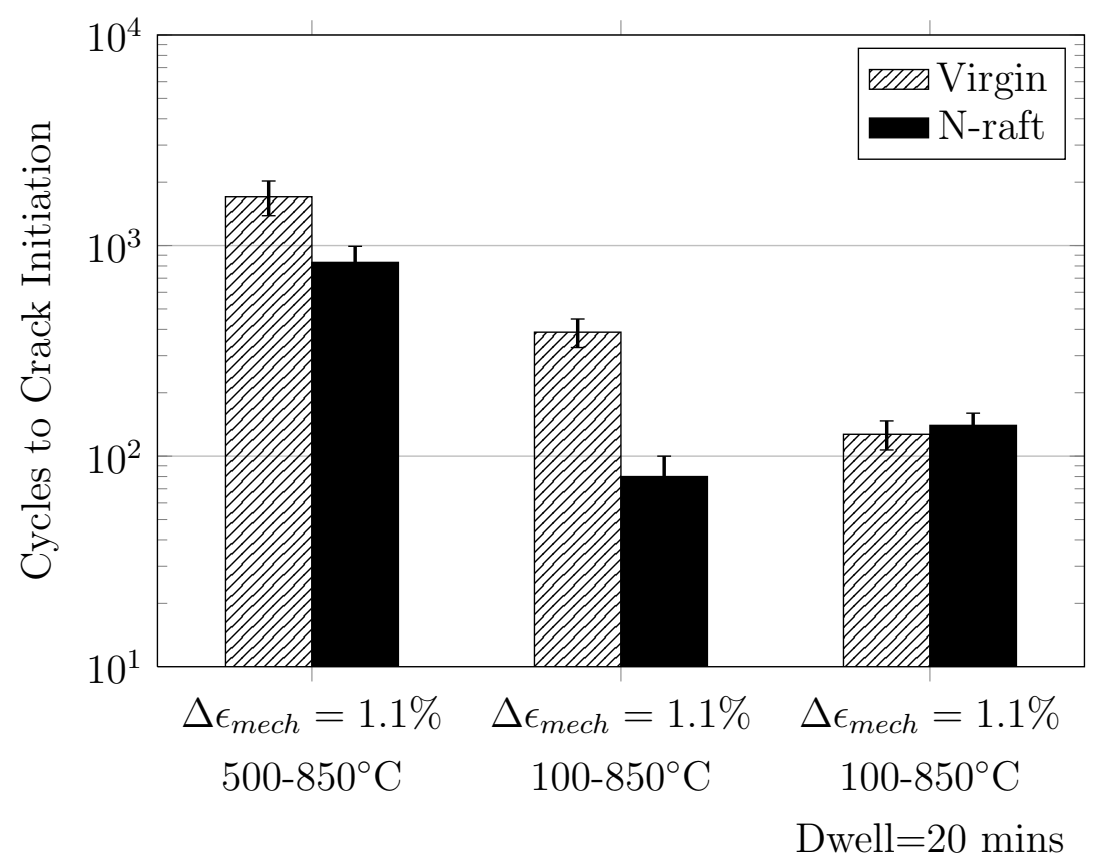

Figure 7: Comparison of lives between N-raft and virgin microstructures under IP TMF conditions for $T_{\max }=850^{\circ} \mathrm{C}$.

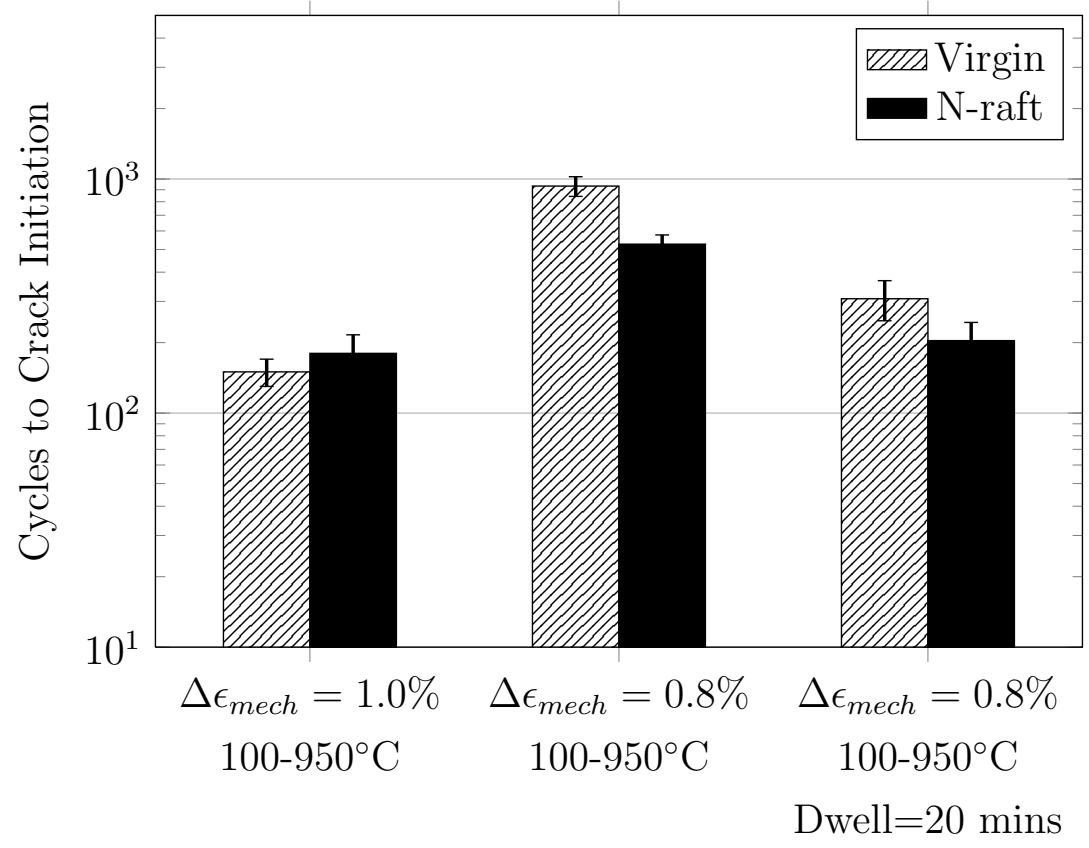

Figure 8: Comparison of lives between N-raft and virgin microstructures under IP TMF conditions for $T_{\max }=950^{\circ} \mathrm{C}$. 

Figure 9: TMF Half-life comparison of virgin and N-raft microstructures under $\mathrm{R}=0, \Delta \epsilon=$ $1.0 \%, \Delta T=100-950^{\circ} \mathrm{C}$ loading conditions where the respective materials are exposed large plastic strains.

An explanation for these life differences can be found by examining the hysteresis response and how it evolves. The N-raft microstructure exhibited similar behavior to that observed in the stress-free coarsened microstructure, in that the mean stresses of the CC TMF experiments on the N-raft microstructure did not relax to the extent exhibited by the virgin microstructure, shown in Figure 10. The reduced relaxation of mean stress at $T_{\max }$ of $850^{\circ} \mathrm{C}$ and $950^{\circ} \mathrm{C}$ resulted in a $20 \%$ on average larger tensile mean stress. Similar experimental findings have been made on CMSX-4 and CMSX-6 single crystals in the N-raft state [32]. N-rafts, lying perpendicular to the loading axis, facilitate fatigue crack growth since fewer $\gamma / \gamma^{\prime}$ interfaces must be traversed by the crack and its crack tip dislocation field.

When increasing the mechanical strain amplitude from 0.8 to $1.0 \%$ under $100-950^{\circ} \mathrm{C}$ IP TMF conditions, the TMF life was observed to become microstructure insensitive as shown in Figure 8, which can be explained by the accelerated rate of the plastic shakedown process reducing the mean tensile stress of the aged microstructure to be comparable to the virgin. For the cases where the N-raft microstructure is tested under $\mathrm{CF}$ conditions, the mean stress in the N-raft microstructure is observed to converge 
The fatigue cracks observed on the surface of the N-raft and virgin specimens are shown in Figure 12. Fatigue cracks in the N-rafted specimens tend to be oriented perpendicular to the loading axis suggesting the orientation of the $\gamma$ channels is facilitating the crack growth direction. Similar findings have been reported for the GTD-111 and CMSX-4 among other Ni-base superalloys $[6,13,15]$. In contrast, the virgin microstructure allows for large scale fatigue crack propagation along the $\{111\}$ planes suggesting the influence of crystallographic slip is dominant. When viewed at a microscopic scale, nucleation of fatigue cracks under these IP TMF conditions is typically observed to occur at the interface of carbides in identical fashion to that seen in Figure 6 for both microstructures. Hence, the state of the microstructure appears to have less of an influence on nucleation and a greater influence on the resistance to either fatigue crack propagation or the coalescing of microcracks that have nucleated at carbides.
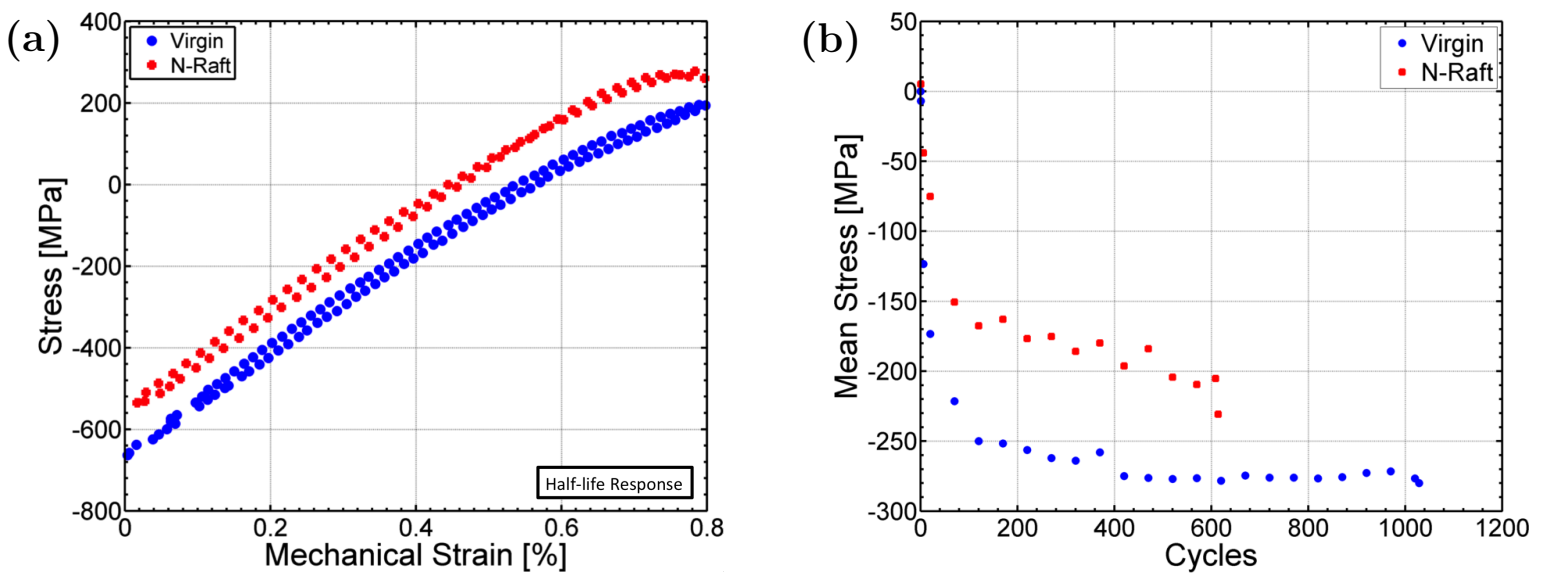

Figure 10: Comparison of N-raft microstructure to the virgin under CC IP TMF conditions ( $\Delta T=100-950^{\circ} \mathrm{C}$ and $R_{\epsilon}=0$ ) showing (a) half-life hysteresis response and (b) mean stress evolution. 


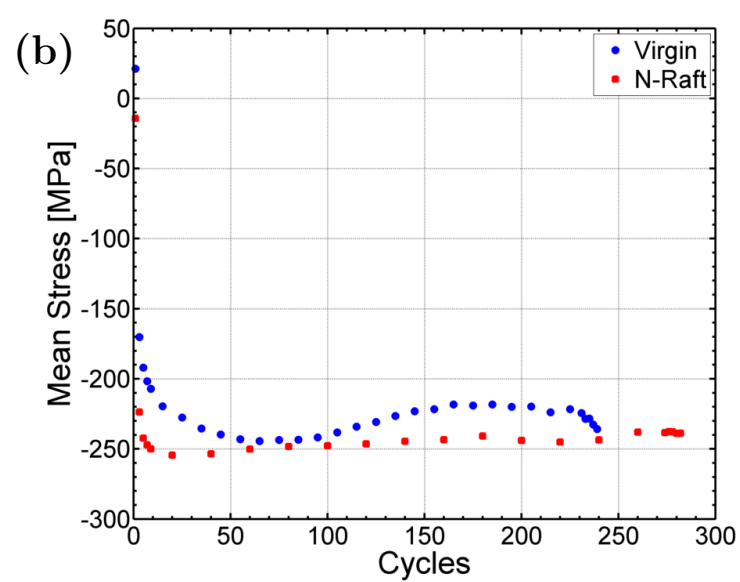

Figure 11: Comparison of N-raft microstructure to the virgin under CF IP TMF conditions ( $\Delta T=100-950^{\circ} \mathrm{C}$ and $R_{\epsilon}=0$ ) showing (a) half-life hysteresis response and (b) mean stress evolution.
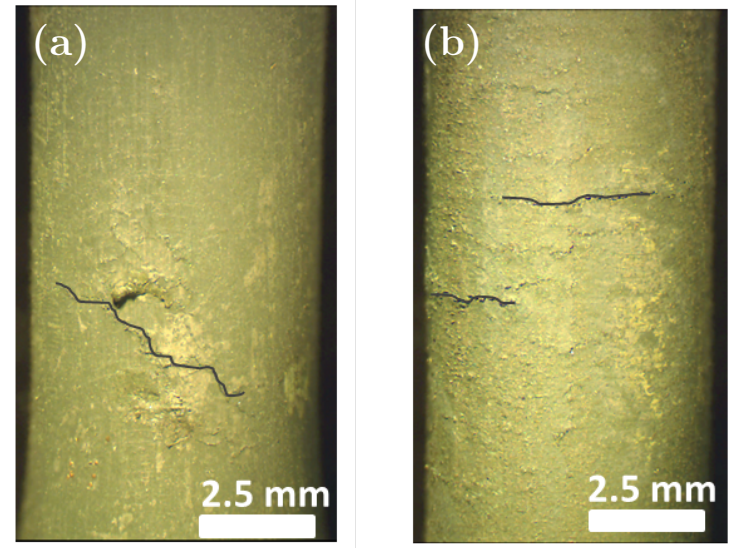

Figure 12: Cracks appearing on surface of specimens that have undergone CC IP TMF $\left(\Delta T=100-950^{\circ} \mathrm{C}\right.$, and $\left.\Delta \epsilon_{m e c h}=0.8 \%\right)$ comparing (a) the virgin microstructure and (b) the N-raft microstructure. Note: The observable surface crack images were enhanced to distinguish from surface undulations in the accumulated oxide layer.

\subsection{TMF of P-raft Microstructure}

P-raft microstructures form in regions near the exterior surfaces of blades that undergo generally OP TMF due to a combination of high temperature exposure and constraint associated with the cooler material surrounding the internal cooling passages [26,33]. Based on the combination of thermal analysis and component analysis, the typical 
conditions where the P-raft microstructure is generated tends to coincide with a maximum surface temperature of $950^{\circ} \mathrm{C}$. Consequently, the relevant loading for P-raft TMF experiments was OP TMF with a $T_{\max }=950^{\circ} \mathrm{C}$ and assuming an idealized $R_{\epsilon}=-\infty$.

The comparison of lives between the P-raft and virgin microstructures is shown in Figure 13. As discussed in a companion paper [28], the life is reduced when $T_{\min }$ lower for the same $T_{\max }$ and mechanical strain amplitude. Under $\mathrm{CC}$ conditions, the life of the P-raft microstructure is further reduced by a factor of two or greater when compared to the virgin material for both $T_{\min }$. Interestingly, when a $20 \mathrm{~min}$. dwell at the maximum compressive strain is introduced, the life of the P-raft microstructure was found to increase by a factor of two over that of the virgin microstructure exposed to the same conditions. In fact, adding the compressive dwell to the P-raft microstructure only marginally reduced the life in comparison to the life of the P-raft microstructure under CC conditions.

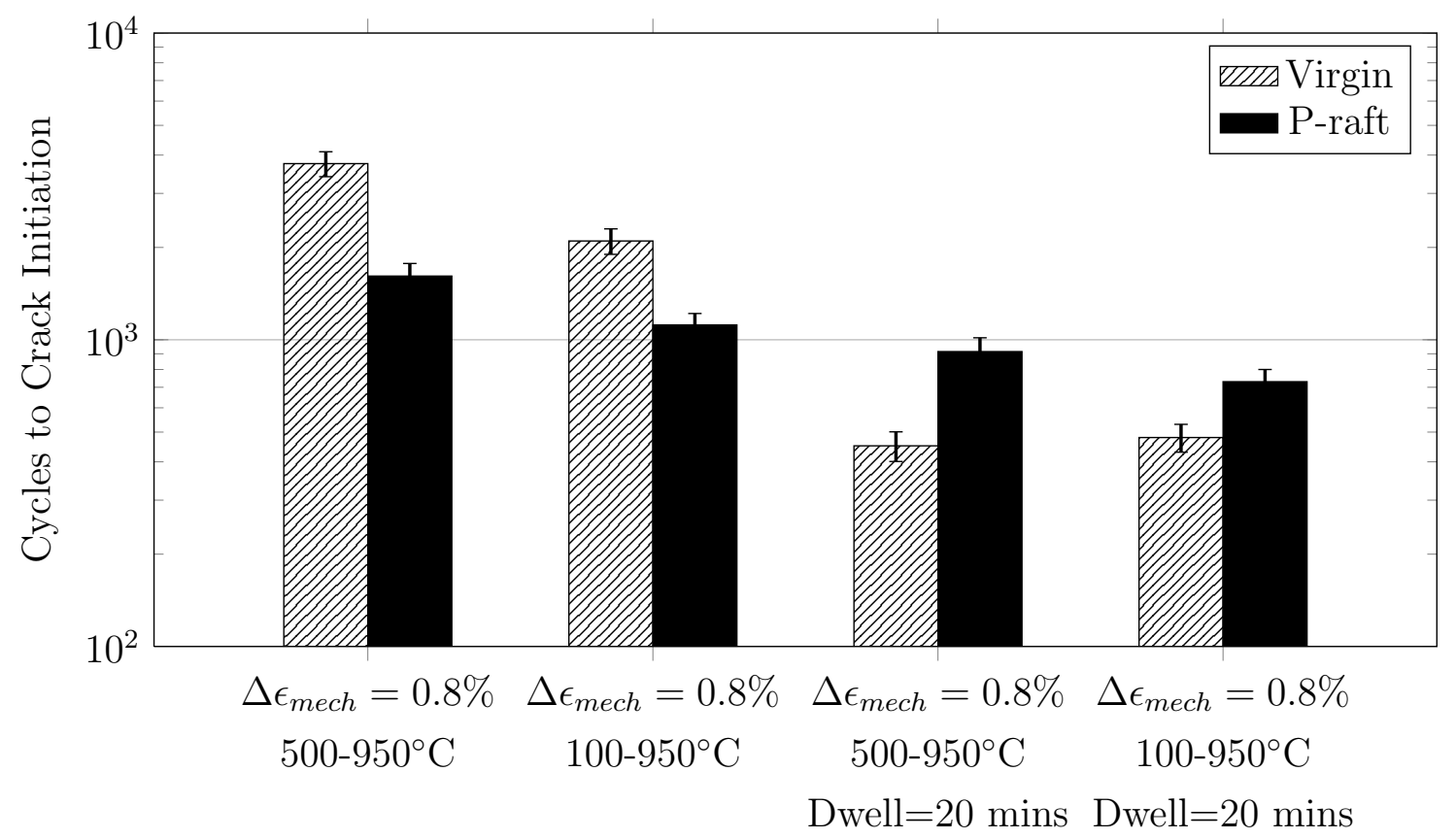

Figure 13: Comparison of lives between P-raft and virgin microstructures under OP TMF conditions.

To understand these life trends, first, the hysteresis loops at half-life are examined, shown in Figure 14 and 15. The hysteresis loops for both microstructures at half life are similar. Overall, the hysteresis response of the aged microstructure is observed to stabilize more quickly than the virgin microstructure, similar to observations made for other TMF conditions. For CC conditions, the reduction in life appears to be 
(a)

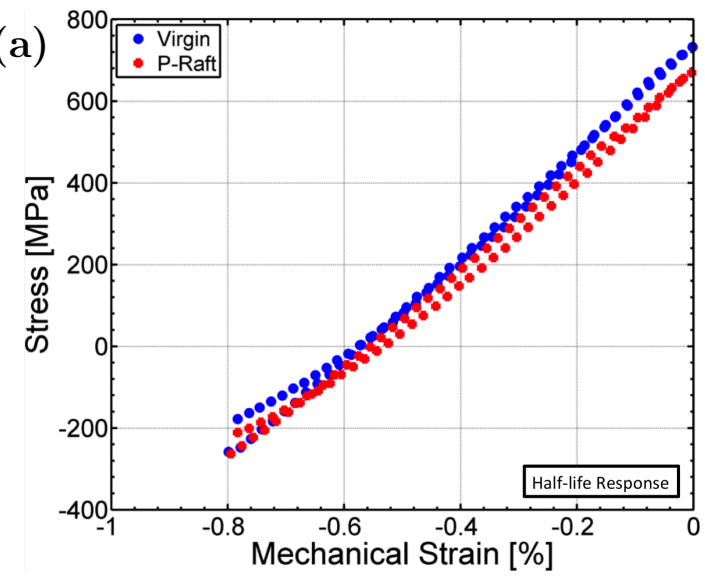

related to the slightly reduced cyclic strength resulting in greater accumulated cyclic inelastic strain. In contrast, in the case of CF cycling, half-life hysteresis responses were nearly identical for both microstructures; though, the mean stress of the virgin material exposed to CF conditions was observed to have an accelerated rate of decline compared to that of the P-raft microstructure as shown in Figure 15. To understand why P-raft microstructure is more resistant to $\mathrm{CF}$ cycling, the fatigue crack nucleation and growth behavior needs to be examined.

Figure 14: Comparison of P-raft microstructure to the virgin under CC OP TMF conditions $\left(\Delta T=100-950^{\circ} \mathrm{C}\right)$ showing (a) half-life hysteresis response and (b) mean stress evolution.
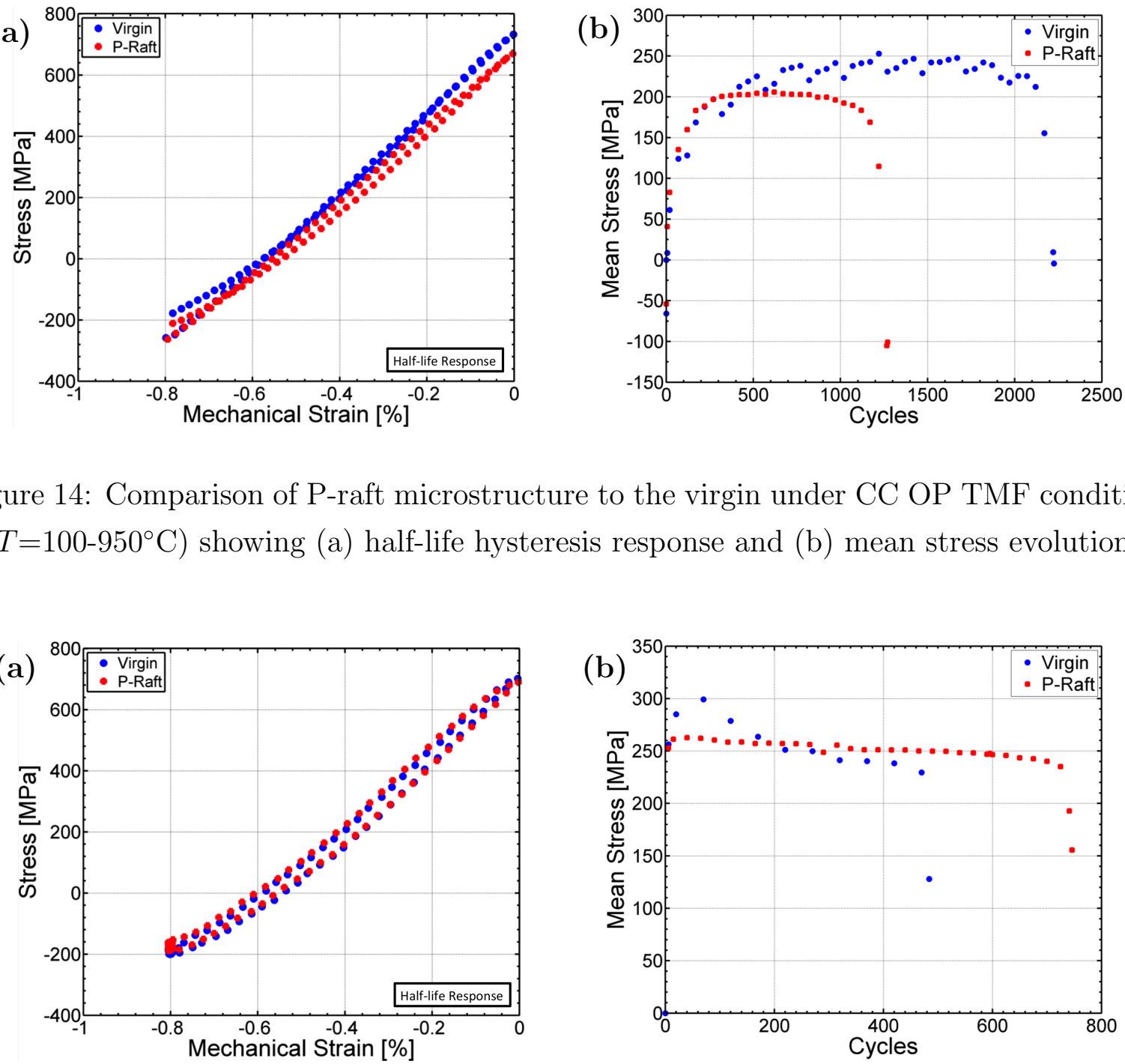

Figure 15: Comparison of P-raft microstructure to the virgin under CF OP TMF conditions $\left(\Delta T=100-950^{\circ} \mathrm{C}\right)$ showing (a) half-life hysteresis response and (b) mean stress evolution.

The macroscopic crack appearance for the four OP TMF experiments are shown 
in Figure 18. Fewer cracks are observed on the surface of the P-raft specimens when compared to the virgin specimens, which exhibited significant surface distortions and multiple cracks. Particularly of note is the difference in the appearance of the surface cracks when exposed to $\mathrm{CF}$ conditions. The virgin specimen exhibits fingernail cracking whereas, cracking in the P-raft microstructure is jagged and appears to exhibit crack linking. The stability of the virgin microstructure was also examined. The $\gamma^{\prime}$ microstructure of the virgin specimen remained generally cuboidal when tested under both $\mathrm{CC}$ and $500-950^{\circ} \mathrm{C} \mathrm{CF}$ conditions, while under $100-950^{\circ} \mathrm{C} \mathrm{CF}$ conditions, the $\gamma^{\prime}$ precipitates underwent morphological transformation into a P-raft state as shown in Figure 16, even though test times were similar. Crack formation and propagation in the virgin specimens tested in OP TMF was observed to have occurred through a progression of cracking along oxidation spikes often following paths in the interdendritic regions. In the case of the P-raft microstructure that formed in the virgin material exposed to $100-950^{\circ} \mathrm{C}$ CF conditions, the net effect of slip bands can be observed cutting through the $\gamma^{\prime}$ rafts (Figure 16) indicating much localized plastic damage occurred in the material prior to the morphological change of the $\gamma^{\prime}$. This may suggest that the increase in cyclic plastic strain in the $T_{\min }$ of $100^{\circ} \mathrm{C} \mathrm{CF}$ test may have helped promote the formation of rafts compared to the other OP TMF conditions that did not result in clear raft formation. The cyclic plastic strain generates dislocations that are absorbed at the $\gamma / \gamma^{\prime}$ interfaces to provide a kinetic path to enable rafting to occur at a faster rate $[30]$. 

$\Delta \epsilon_{\text {mech }}=0.8 \%$ ) showing that the initial cuboidal $\gamma^{\prime}$ particles form P-rafts under this condition. Note the appearance of slip bands that likely form at the minimum temperature of the cycle.

When the P-raft microstructure is exposed to CF conditions, the crack is observed to have deflected and grow parallel to the applied load and raft orientation in the same direction as the $\gamma$ channels (Figure 17). Hence, it appears that the benefit of the P-raft microstructure in increasing the CF OP TMF life is associated with the promotion of crack deflection promoted by the raft orientation. These crack deflections are typically observed in the dendritic regions which have the strongest tendency to raft. This crack deflection is not observed in the virgin microstructure. In addition, fewer cracks are observed in the P-raft microstructure due to the ability for this microstructure to blunt and arrest cracks more readily than the virgin microstructure where multiple large cracks are observed in CF OP TMF conditions (Figure 18). In other reported cases where fatigue on P-raft microstructures has been performed, similar observations have been made on the deflection of the crack parallel to the $\gamma^{\prime}$ within the dendritic regions $[16,17,32,34]$. 


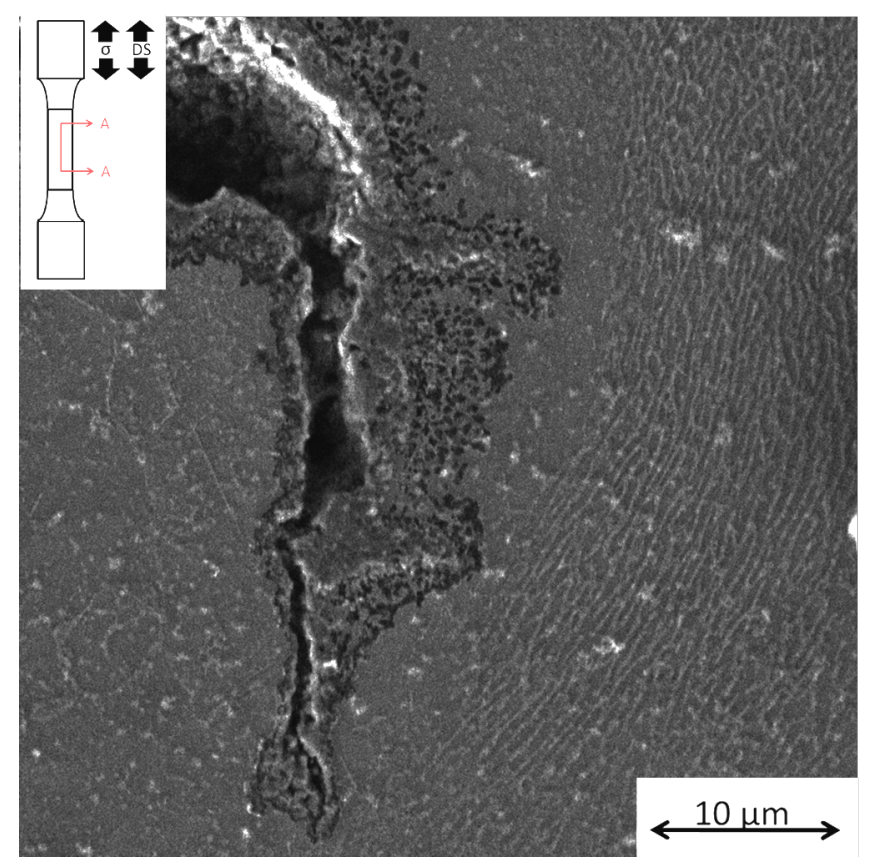

Figure 17: Example of deflection of fatigue crack in a P-raft microstructure under OP TMF $\left(\Delta T=100-950^{\circ} \mathrm{C}\right.$ and $\left.\Delta \epsilon_{m e c h}=0.8 \%\right)$.
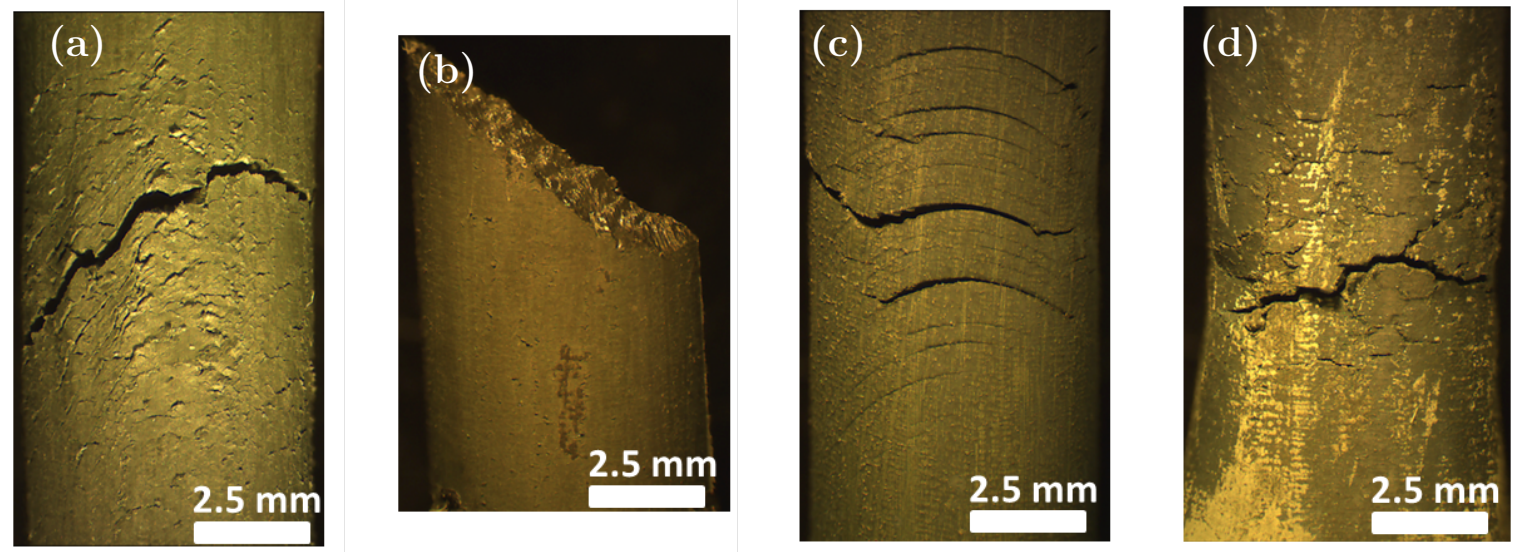

Figure 18: Crack appearances on surfaces of material exposed to OP TMF, $\Delta T=100-950^{\circ} \mathrm{C}$, $\Delta \epsilon_{\text {mech }}=0.8 \%$ for (a) Virgin microstructure CC (b) P-raft microstructure CC (c) Virgin microstructure CF (d) P-raft microstructure CF.

In Ni-base superalloys, the rate determining step for the propagation of fatigue cracks has been rate at which the fatigue crack progresses through the primary dendrites [35]. Under the conditions considered in this study, all of the OP TMF cracks nucleate in the same manner through the formation of a surface oxide spike regardless 


\section{Summary and Conclusions}

As has been shown, the lives of the aged microstructures of this DS Ni-base superalloy are always less than or at best the same as the virgin microstructure, except in the case of P-rafted microstructure. A P-rafted microstructure has greater crack initiation lives under $\mathrm{CF}$ conditions. A summary of the effects of aged microstructures and TMF loading type is given in Table 2. Based on the results of this and prior work, some general principles can be deduced:

- Nucleation of cracks under IP TMF occurs at carbides, located in the interdendritic regions, either through carbide cracking or cyclic plasticity near the inter- 

TMF occurs through an oxide spike mechanism involving an interaction between cyclic loading and oxidation. Neither crack nucleation mechanism appears to be strongly dependent on the $\gamma / \gamma^{\prime}$ rafted microstructure condition.

- In contrast, the microcrack propagation resistance does show dependence on the state of the aged microstructure.

- The stress-free coarsened microstructure exhibited a reduced IP TMF life when compared to the virgin microstructure. The aged microstructure maintained higher tensile mean stress due to the absence of large internal misfits stresses that can promote accelerated cyclic plastic stress relaxation.

- The N-raft microstructure was also exhibited a reduced IP TMF life when compared to the virgin microstructure. The alignment of the $\gamma^{\prime}$ rafts normal to the cyclic loading provided a preferred avenue for fatigue crack propagation.

- Most cracks that were observed to propagate into the matrix in the P-raft microstructure were observed to have arrested in contrast to the virgin microstructure. The arrests are associated with crack deflections that occur due to the interaction of the crack and crack tip plastic fields with the $\gamma / \gamma^{\prime}$ interfaces.

- Rapid paths for oxygen penetration along the dilated $\gamma / \gamma^{\prime}$ interfaces are much more extensive normal to the loading direction in the N-raft microstructure and aligned with the loading direction in the P-raft microstructure. It is well established that oxidation and oxygen penetration reduces the life in Ni-base superalloys particularly under OP TMF where these oxides cannot sustain large tensile stress at the minimum temperature of the cycle. This factor reduces the life of the N-rafted material compared to the P-raft microstructure and likely helps promote crack deflection in the P-raft microstructure undergoing OP TMF.

- In addition, the creep and time-dependent plasticity response is restricted in the P-raft microstructure $[13,16]$, because the $\gamma^{\prime}$ becomes more impenetrable with increasing temperature as discussed by various investigators $[38,39]$.

- Unlike the other aged microstructure states, P-rafts were observed to be beneficial in enhancing the OP TMF life when a dwell is imposed at the maximum temperature and minimum strain ( $\mathrm{CF}$ condition). When compared to the virgin microstructure, a $2 \mathrm{x}$ increase was observed. Interestingly, this benefit was not observed under $\mathrm{CC}$ conditions. This finding can be explained by the P-raft microstructure restricting dislocation activity and crack growth to the vertical $\gamma$ channels when exposed to temperatures above $800^{\circ} \mathrm{C}$. Below $800^{\circ} \mathrm{C}$, shearing 
of the $\gamma^{\prime}$ rafts due to lack of horizontal $\gamma$ channels to permit lateral dislocation motion enhances the incurred damage. Ultimately, the P-raft material exposed to CC conditions spent $75 \%$ of the cycle time at temperatures that promoted $\gamma^{\prime}$ shearing, while the P-raft material exposed to CF conditions spent $75 \%$ of the time at temperatures that promoted conditions including oxidation along the vertical $\gamma / \gamma^{\prime}$ interfaces inducing crack deflection.

\section{Acknowledgment}

The authors would like to thank Siemens Energy Inc., Orlando, FL for supporting this work through subcontract to DOE Award DE-FC26-05NT42644 on Advanced Hydrogen Turbine Development. 


\section{$6 \quad$ References}

[1] Beardmore, P., Davies, R. G., and Johnston, T. L., 1969. "On the Temperature Sependence of the Flow Stress of Nickel-base Alloys". Transactions of the Metallurgical Society of AIME, 245, pp. 1537-1545.

[2] Chen, W., and Immarigeon, J.-P., 1998. "Thickening behaviour of precipitates in nickel base superalloys during rafting". Scripta Materialia, 39(2), pp. 167 - 174.

[3] Mughrabi, H., and Tetzlaff, U., 2000. "Microstructure and High-Temperature Strength of Monocrystalline Nickel-Base Superalloys". Advanced Engineering Materials, 2(6), pp. 319-326.

[4] Reed, R. C., 2006. The Superalloys Fundamentals and Applications. Cambridge University Press.

[5] Biermann, H., Tetzlaff, U., Mughrabi, H., von Grossmann, B., and andTamas Ungar, S., 2000. "Investigations on the Orgin and Effect of Anomalous Rafting". In Superalloys 2000, T. Pollock, R. Kissinger, R. Bowman, K. Green, M. McLean, S. Olson, and J. Schirra, eds., TMS, pp. 525-534.

[6] Epishin, A., Link, T., Klingelhöffer, H., Fedelich, B., and Portella, P., 2010. "Creep Damage of Single-crystal Nickel base Superalloys: Mechanisms and Effect on Low Cycle Fatigue". Materials at High Temperatures, 27(1), pp. 53 - 59.

[7] Buffiere, J., and Ignat, M., 1995. "A Dislocation Based Criterion for the Raft Formation in Nickel-based Superalloys Single Crystals". Acta Metallurgica et Materialia, 43(5), pp. 1791-1797.

[8] Veon, M., Brechet, Y., and Louchet, F., 1996. "Directional Coarsening of Nickel Based Superalloys: Driving Force and Kinetics". In Superalloys 1996, M. Veron, Y. Brechet, and F. Louchet, eds., TMS, pp. 181-190.

[9] Pollock, T., and Field, R., 2002. Dislocations and High-Temperature Plastic Deformation of Superalloy Single Crystals, Vol. 11 of Dislocations in Solids. Elsevier Science.

[10] Schneider, W., Hamme, J., and Mughrabi, H., 1992. "Creep Deformation and Rupture behavior of the Monocrystalline Superalloy CMSX-4 - A Comparison with the Alloy SRR 99". In Superalloys 1992, S. Antolovich, R. Stusrud, R. MacKay, D. Anton, T. Khan, R. Kissinger, and D. Klarstrom, eds., TMS, pp. 589-598.

[11] Nabarro, F. R. N., and de Villiers, F., 1995. Physics of Creep and Creep Resistant Alloys. CRC Press.

[12] Antolovich, S. D., Baur, R., and Liu, S., 1980. "A Mechanistically Based Model for high Temperature LCF of Ni Base Superalloys". In Superalloys 1980, TMS, pp. 605-613.

[13] Ott, M., and Mughrabi, H., 1999. "Dependence of the high-temperature low-cycle fatigue behaviour of the monocrystalline nickel-base superalloys CMSX-4 and CMSX-6 on the $\gamma / \gamma^{\prime}$ morphology". Materials Science and Engineering: A, 272(1), pp. $24-30$. 
[14] Gordon, A. P., Neu, R. W., and McDowell, D. L., 2009. "Effect of pre-exposure on crack initiation life of a directionally solidified Ni-base superalloy". International Journal of Fatigue, 31(2), pp. 393 - 401.

[15] Engler-Pinto, C., Noseda, C., Nazmy, M., and Rezai-Aria, F., 1996. "Interaction Between Creep and Thermo-mechanical Fatigue of CM247LC-DS". In Superalloys 1996, R. K. D. Deye, D. Anton, and A. Cetel, eds., TMS, pp. 319-325.

[16] Neuner, F. C., Tetzlaff, U., and Mughrabi, H., 2002. "Enhancement of Thermomechanical Fatigue Resistance of a Monocrystalline Nickel-base Superalloy by Pre-rafting". In Thermomechanical Fatigue Behavior of Materials, A. McGaw, S. Kalluri, J. Bressers, and S. D. Peteves, eds., Vol. 4 of ASTM STP 1428. ASTM International.

[17] Tetzlaff, U., and Mughrabi, H., 2000. "Can High Temperature Tensile Strength of Nickelbase Superalloys be Improved by Pre-Rafting?". In Intermetallics and Superalloys,, D. G. Morris and D. Gareth, eds., Vol. 10, EUROMAT 1999, Wiley-VCH, pp. 22-27.

[18] Arrell, D., Hasselqvist, M., Sommer, C., and Moverare, J., 2004. "On TMF Damage, Degradation Effects, and the Associated $T_{\min }$ Influence on TMF Test Results in $\gamma / \gamma^{\prime}$ prime Alloys". In Superalloys 2004, pp. 291-294.

[19] Kupkovits, R. A., and Neu, R. W., 2010. "Thermomechanical fatigue of a directionallysolidified Ni-base superalloy: Smooth and cylindrically-notched specimens". International Journal of Fatigue, 32(8), pp. 1330 - 1342.

[20] Mughrabi, H., 2009. "Microstructural Aspects of High Temperature Deformation of Monocrystalline Nickel Base Superalloys: Some Open Problems". Materials Science and Technology, 25(2), pp. 191-204.

[21] Harris, K., Erickson, G., and Schwer, R., 1984. "MAR-M247 Derivative-CM247LC-DS Alloy CMSX Single Crystal Alloys Properties and Performance". In Superalloys 1984, pp. 221-230.

[22] Sims, C., 1972. The Superalloys. John Wiley and Sons.

[23] Kirka, M. M., 2014. "Thermomechanical Behavior of a Directionally Solidified Nickelbase Superalloy in the Aged State". PhD thesis, Georgia Institute of Technology.

[24] ASTM E606-12 Standard Practice for Strain-Controlled Fatigue Testing. Tech. rep., ASTM International.

[25] ASTM E2368-10 Standard Practice for Strain Controlled Thermomechanical Fatigue Testing. Tech. rep., ASTM International.

[26] Lee, S.-S., Lee, J. H., Park, I. K., Song, S.-J., and Choi, M. Y., 2006. "ThermoMechanical Fatigue of the Nickel Base Superalloy IN738LC for Gas Turbine Blades". Key Engineering Materials, 321 - 323, pp. 509-512.

[27] Fedelich, B., Epishin, A., Link, T., Klingelhöffer, H., Künecke, G., and Portella, P. D., 2012. "Rafting During High Temperature Deformation in a Single Crystal Superalloy: Experiments and Modeling". In Superalloys 2012, E. Huron, R. Reed, M. Hardy, M. Mills, R. Montero, P. Portella, and J. Telesman, eds., pp. 491-500. 

Ni-base Superalloy". Submitted for Review to the International Journal of Fatigue.

[29] Argon, A., 2007. Strengthening Mechanisms in Crystal Plasticity. Oxford University Press, USA.

[30] Matan, N., Cox, D., Rae, C., and Reed, R., 1999. "On the kinetics of rafting in CMSX-4 superalloy single crystals". Acta Materialia, 47(7), pp. 2031 - 2045.

[31] Gordon, A., 2006. "Crack Initiation Modeling of a Directionally-Solidified Nickel-Base Superalloy". PhD thesis, Georgia Institute of Technology.

[32] Mughrabi, H., Ott, M., and Tetzlaff, U., 1997. "New Microstructural Concepts to Optimize the High-temperature Strength of $\gamma^{\prime}$-hardened Monocrystalline Nickel-based Superalloys". Materials Science and Engineering: A, 234-236, pp. 434-437.

[33] Draper, S., Hull, D., and Dreshfield, R., 1989. "Observations of Directional Gamma Prime Coarsening During Engine Operation". Metallurgical and Materials Transactions A, 20, pp. 683-688.

[34] Ott, M., Tetzlaff, U., and Mughrabi, H., 1999. "Influence of Directional Coarsening on the isothermal High-Temperature Fatigue Behavior of the Monocrystalline NickelBase Superalloys CMSX-6 and CMSX-4". In Microstructure and Mechanical Properties of Metallic High-temperature Materials, H. Mughrabi, G. Gottsteing, H. Mecking, H. Riedel, and J. Tobolski, eds. WILEY-VCH, pp. 425-440.

[35] Okada, M., Tsutsumi, M., Kitamura, T., and Ohtani, R., 1998. "Initiation and Growth of Small Cracks in Directionally Solidified Mar-M247 Under Creep-Fatigue Part I: Effect of Microstructure". Fatige and Fracture of Engineering Materials and Structures, 21, pp. 741-750.

[36] Shui, L., Jin, T., Tian, S., and Hu, Z., 2007. "Influence of precipitate morphology on tensile creep of a single crystal nickel-base superalloy". Materials Science and Engineering: A, 454-455(0), pp. $461-466$.

[37] Shui, L., Tian, S., Jin, T., and Hu, Z., 2006. "Influence of pre-compression on microstructure and creep characteristic of a single crystal nickel-base superalloy". Materials Science and Engineering: A, 418(1-2), pp. 229 - 235.

[38] Lall, C., Chin, S., and Pope, D., 1979. "The Orientation and Temperature Dependence of the Yield Stress of Ni3 (Al, Nb) Single Crystals". Metallurgical Transactions A, 10(9), pp. 1323-1332.

[39] Webb, G., de Bussac, A., and Antolovich, S. D. “, 1991.”. In High Temperature Ordered Intermetallic Alloys IV, L. A. Johnson, D. P. Pope, and J. O. Stiegler, eds., Vol. 213 of Materials Research Society Symposium Proceedings, p. 235. 


\section{List of Tables}

1 Nominal chemical composition of the DS Ni-base superalloy used in this work given as weight percent $[21] . \ldots$. . . . . . . . . . . . . . . 4

2 Summary of the effect of aged microstructure on life compared to virgin mi- 


\section{List of Figures}

1 Comparison of microstructures: (a) virgin, (b) stress-free coarsened, (c) Nraft, and (d) P-raft. . . . . . . . . . . . . . . . 5

2 Cylindrical specimen with dimensions in mm. . . . . . . . . . . . 6

3 Comparison of lives between the stress-free coarsened and virgin microstructures under IP TMF loading conditions. . . . . . . . . . . . . . . . 8

4 Comparison of stress-free coarsened microstructure to the virgin under CC IP TMF conditions $\left(\Delta T=100-750^{\circ} \mathrm{C}\right)$ showing (a) half-life hysteresis response and (b) mean stress evolution. . . . . . . . . . . . . . . . . . 9

5 Comparison of stress-free coarsened microstructure to the virgin under $\mathrm{CF}$ IP TMF conditions $\left(\Delta T=100-750^{\circ} \mathrm{C}\right)$ showing (a) half-life hysteresis response and (b) mean stress evolution. . . . . . . . . . . . . . . . .

6 Debonded/cracked carbide located at a dendritic-interdendritic boundary within stress-free coarsened microstructure after exposure to IP TMF CC conditions $\left(\Delta T=500-750^{\circ} \mathrm{C}\right.$ and $\left.\Delta \epsilon_{m e c h}=1.2 \%\right) \ldots \ldots \ldots$. . . . . . . . 10

7 Comparison of lives between N-raft and virgin microstructures under IP TMF conditions for $T_{\max }=850^{\circ} \mathrm{C} \ldots \ldots \ldots \ldots \ldots \ldots$

8 Comparison of lives between N-raft and virgin microstructures under IP TMF conditions for $T_{\max }=950{ }^{\circ} \mathrm{C} \ldots \ldots \ldots \ldots \ldots \ldots \ldots$

9 TMF Half-life comparison of virgin and N-raft microstructures under $\mathrm{R}=0$, $\Delta \epsilon=1.0 \%, \Delta T=100-950^{\circ} \mathrm{C}$ loading conditions where the respective materials are exposed large plastic strains. . . . . . . . . . . . . . 13

10 Comparison of N-raft microstructure to the virgin under CC IP TMF conditions $\left(\Delta T=100-950^{\circ} \mathrm{C}\right.$ and $\left.R_{\epsilon}=0\right)$ showing (a) half-life hysteresis response and (b) mean stress evolution. . . . . . . . . . . . . . . . . . 14 
11 Comparison of N-raft microstructure to the virgin under CF IP TMF conditions $\left(\Delta T=100-950^{\circ} \mathrm{C}\right.$ and $\left.R_{\epsilon}=0\right)$ showing (a) half-life hysteresis response and (b) mean stress evolution. . . . . . . . . . . . . . . .

12 Cracks appearing on surface of specimens that have undergone CC IP TMF $\left(\Delta T=100-950^{\circ} \mathrm{C}\right.$, and $\left.\Delta \epsilon_{m e c h}=0.8 \%\right)$ comparing (a) the virgin microstructure and (b) the N-raft microstructure. Note: The observable surface crack images were enhanced to distinguish from surface undulations in the accumulated oxide layer. . . . . . . . . . . . . . . . . . . .

13 Comparison of lives between P-raft and virgin microstructures under OP TMF conditions. . . . . . . . . . . . . . . . . . . . 16

14 Comparison of P-raft microstructure to the virgin under CC OP TMF conditions $\left(\Delta T=100-950^{\circ} \mathrm{C}\right)$ showing (a) half-life hysteresis response and (b) mean stress evolution. . . . . . . . . . . . . . . . . . 17

15 Comparison of P-raft microstructure to the virgin under CF OP TMF conditions $\left(\Delta T=100-950^{\circ} \mathrm{C}\right)$ showing (a) half-life hysteresis response and (b) mean stress evolution. . . . . . . . . . . . . . . . . .

16 Microstructure of virgin specimen after CF OP TMF $\left(\Delta T=100-950^{\circ} \mathrm{C}\right.$ and $\left.\Delta \epsilon_{\text {mech }}=0.8 \%\right)$ showing that the initial cuboidal $\gamma^{\prime}$ particles form P-rafts under this condition. Note the appearance of slip bands that likely form at the minimum temperature of the cycle. . . . . . . . . . . . . . . . . 19

17 Example of deflection of fatigue crack in a P-raft microstructure under OP $\operatorname{TMF}\left(\Delta T=100-950^{\circ} \mathrm{C}\right.$ and $\left.\Delta \epsilon_{m e c h}=0.8 \%\right) \ldots \ldots \ldots$

18 Crack appearances on surfaces of material exposed to OP TMF, $\Delta T=100$ $950^{\circ} \mathrm{C}, \Delta \epsilon_{\text {mech }}=0.8 \%$ for (a) Virgin microstructure CC (b) P-raft microstructure CC (c) Virgin microstructure CF (d) P-raft microstructure CF. . . . . . 


\section{IP}

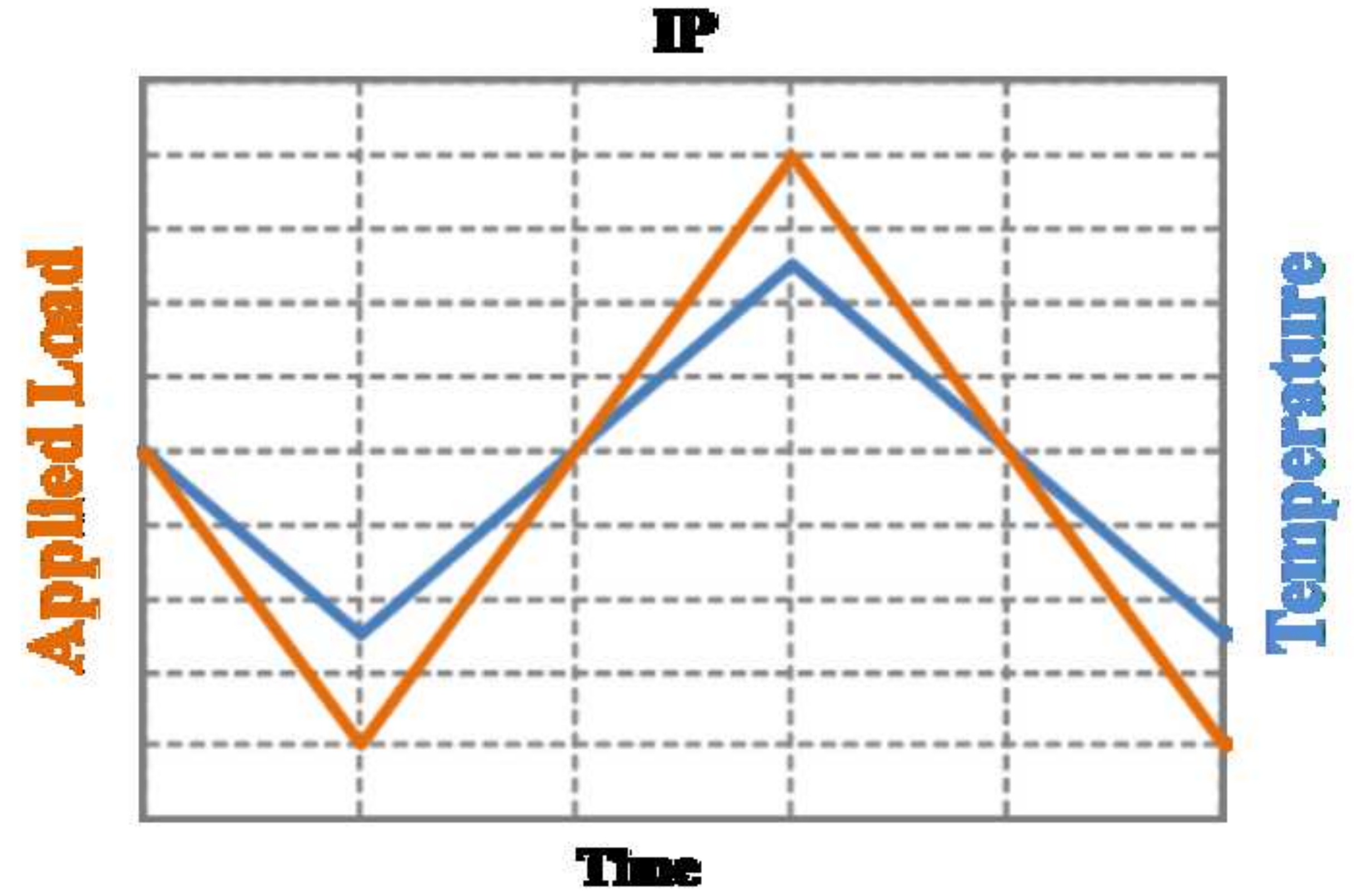

\section{This:}




\section{OP}

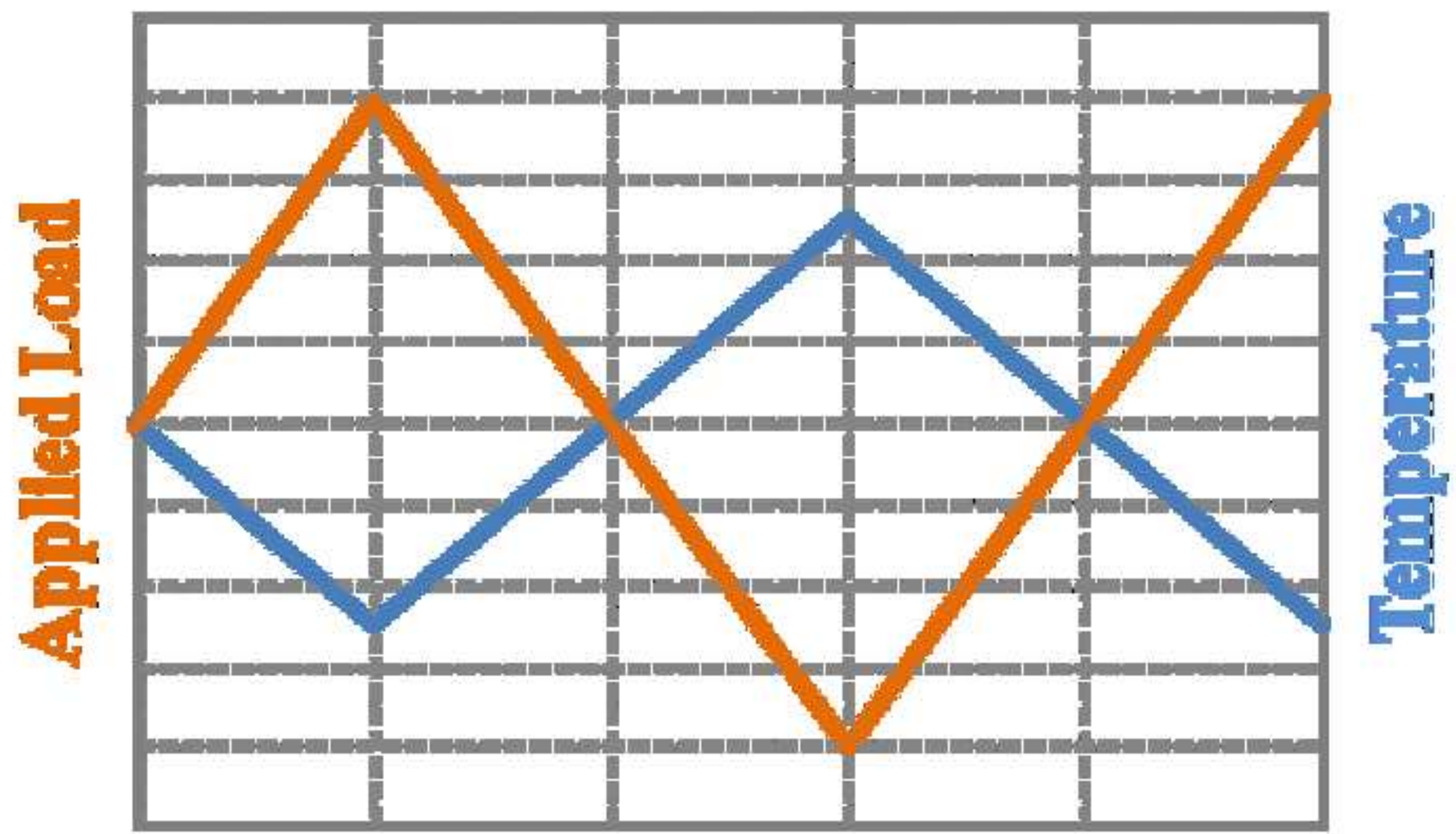

\section{In I}




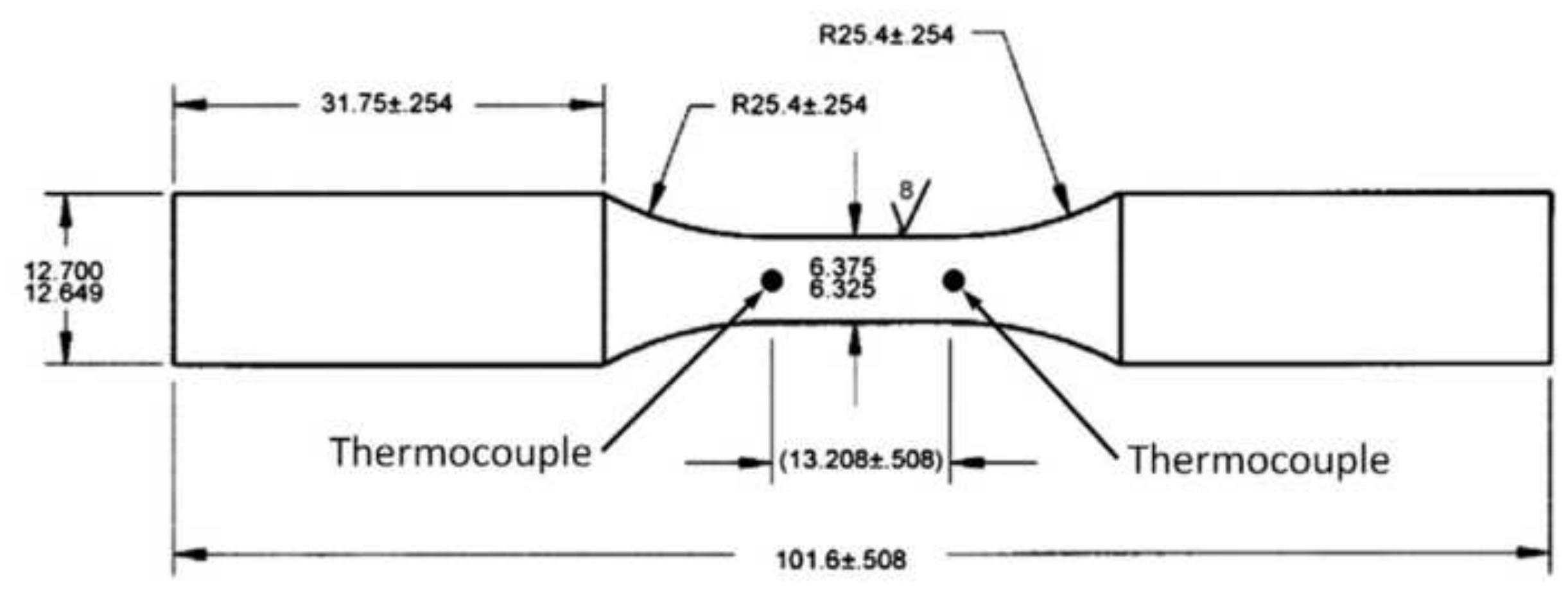




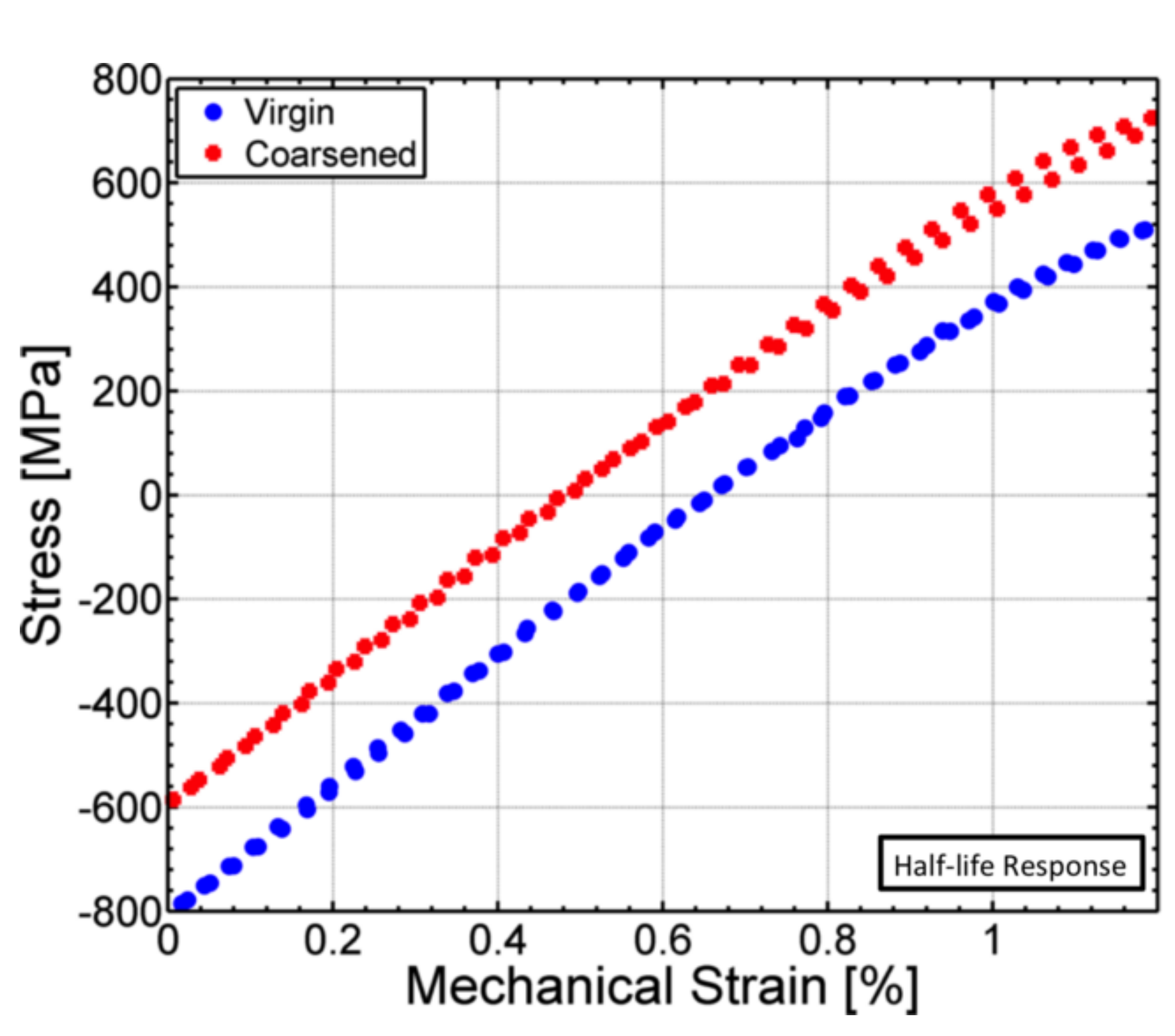

.

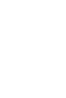




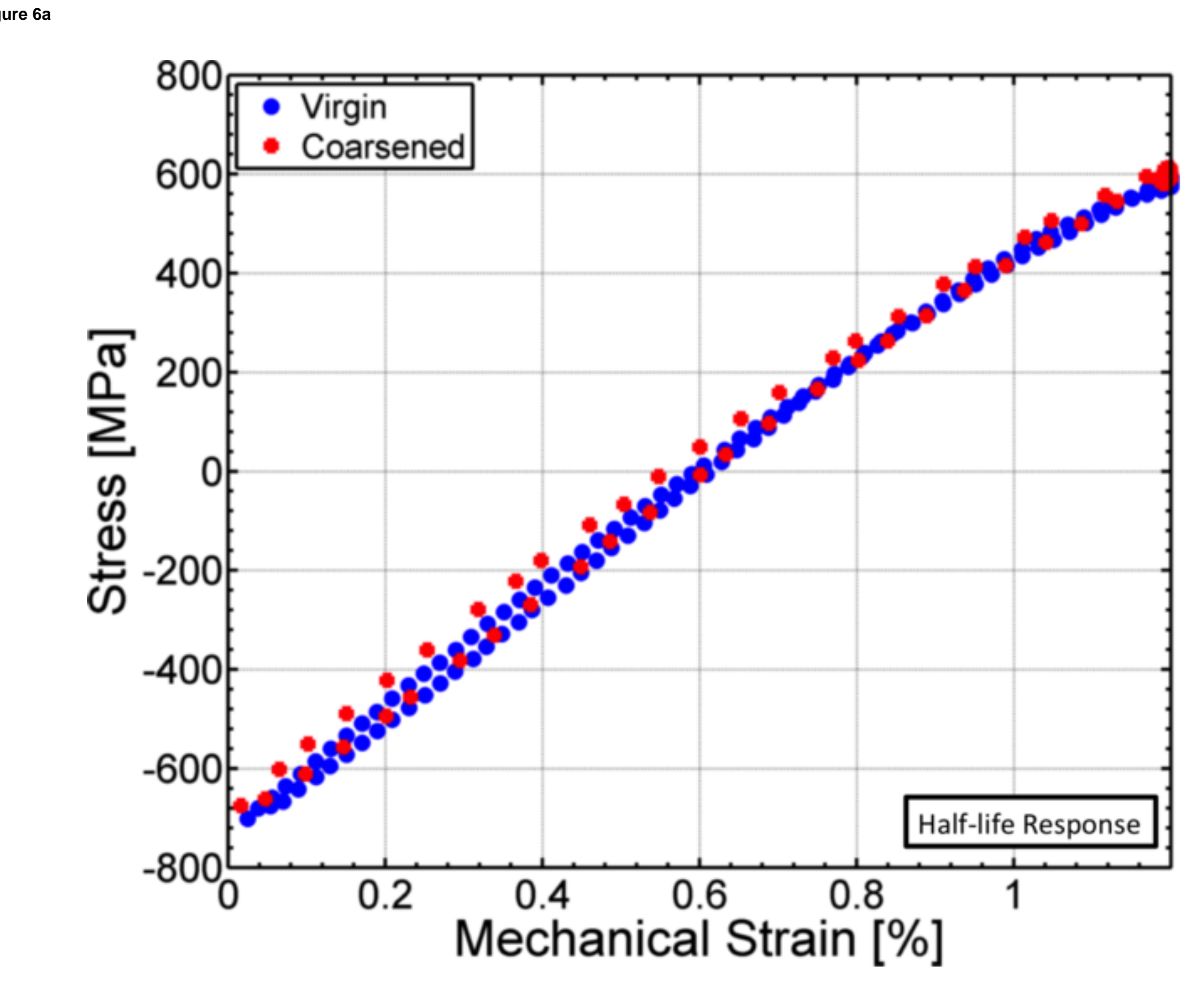

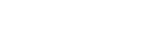 \\ .}

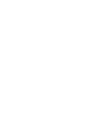

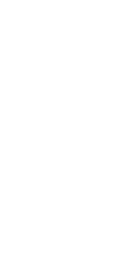

.
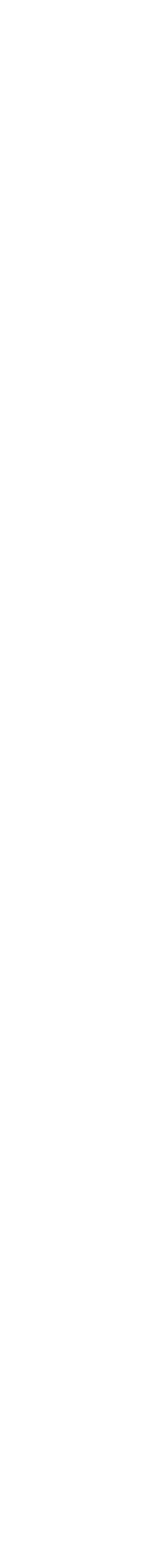


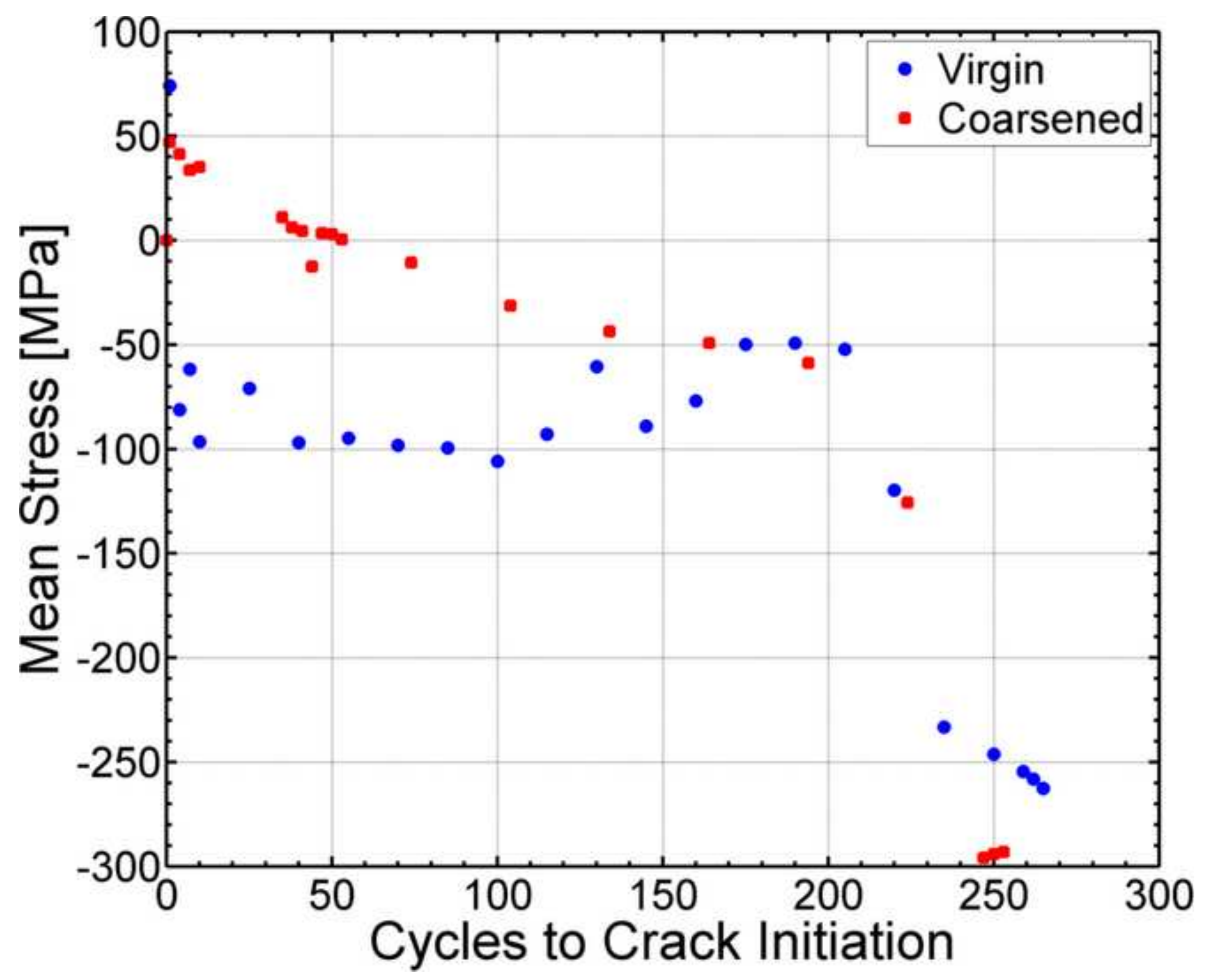




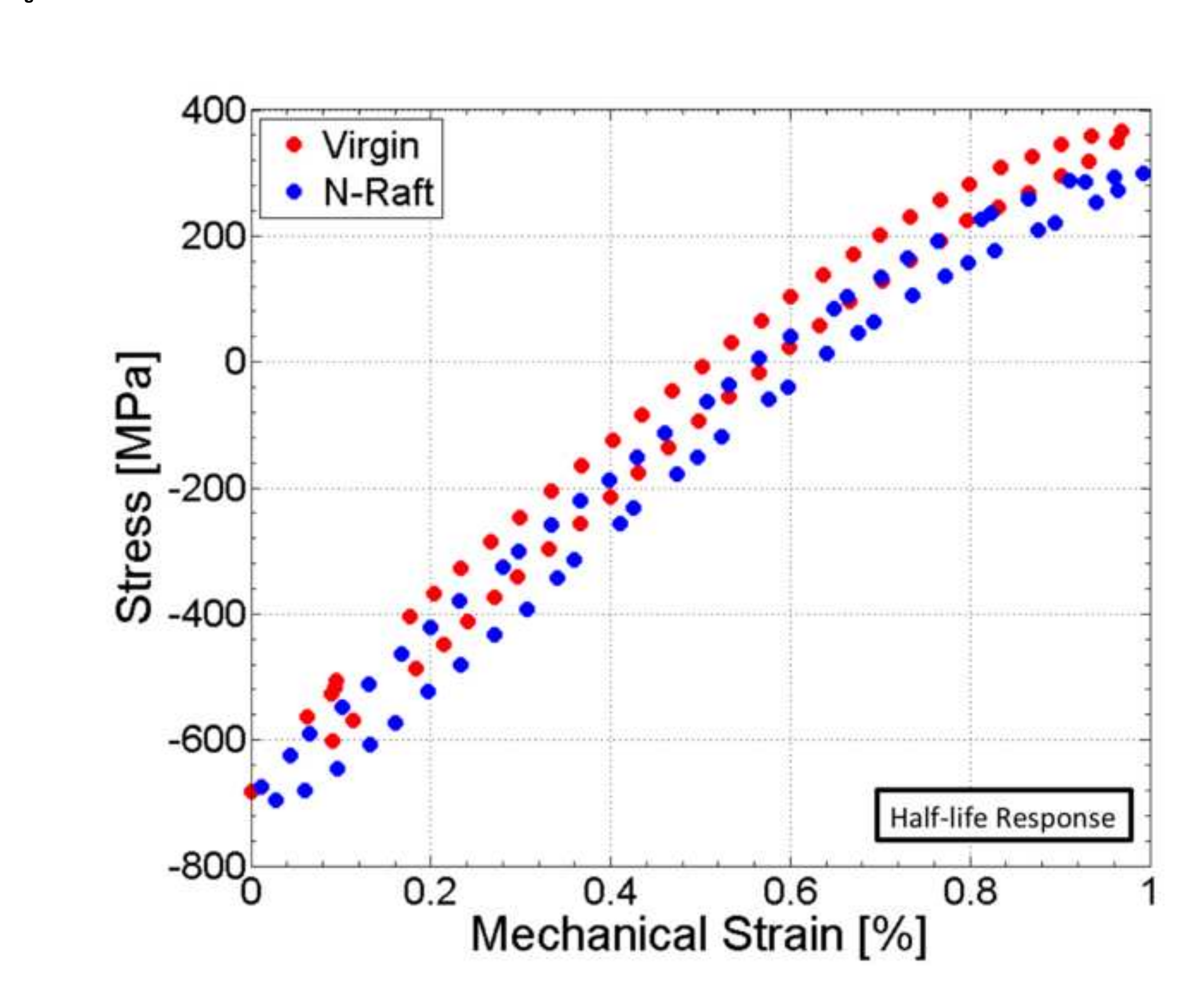

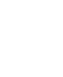

.
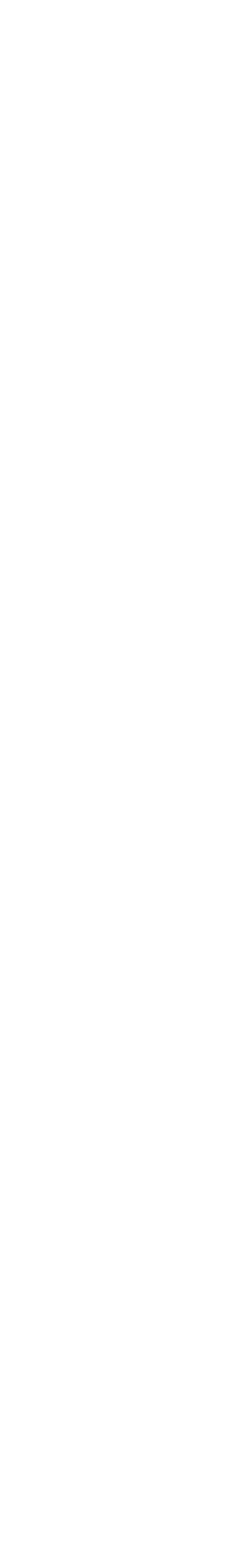


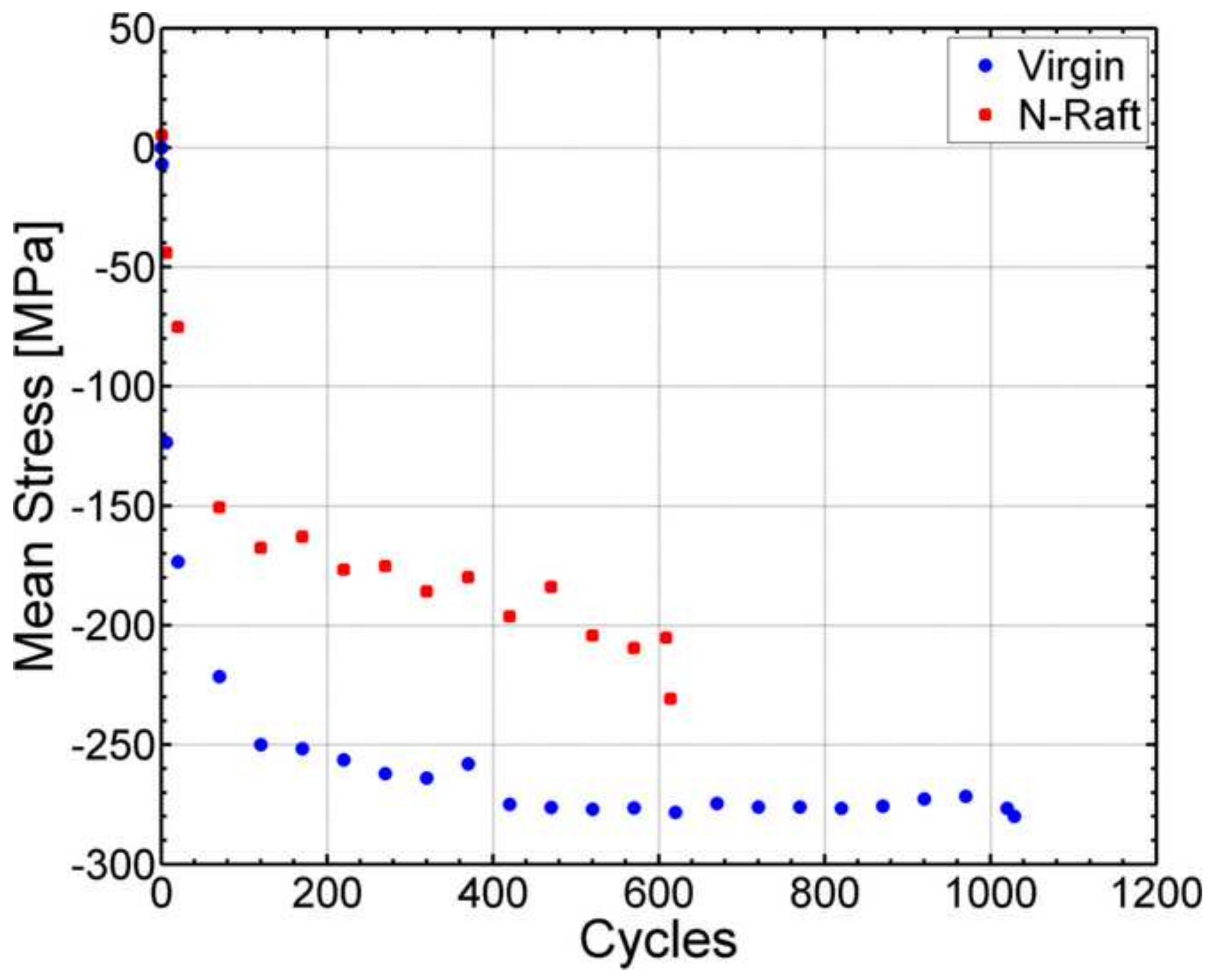




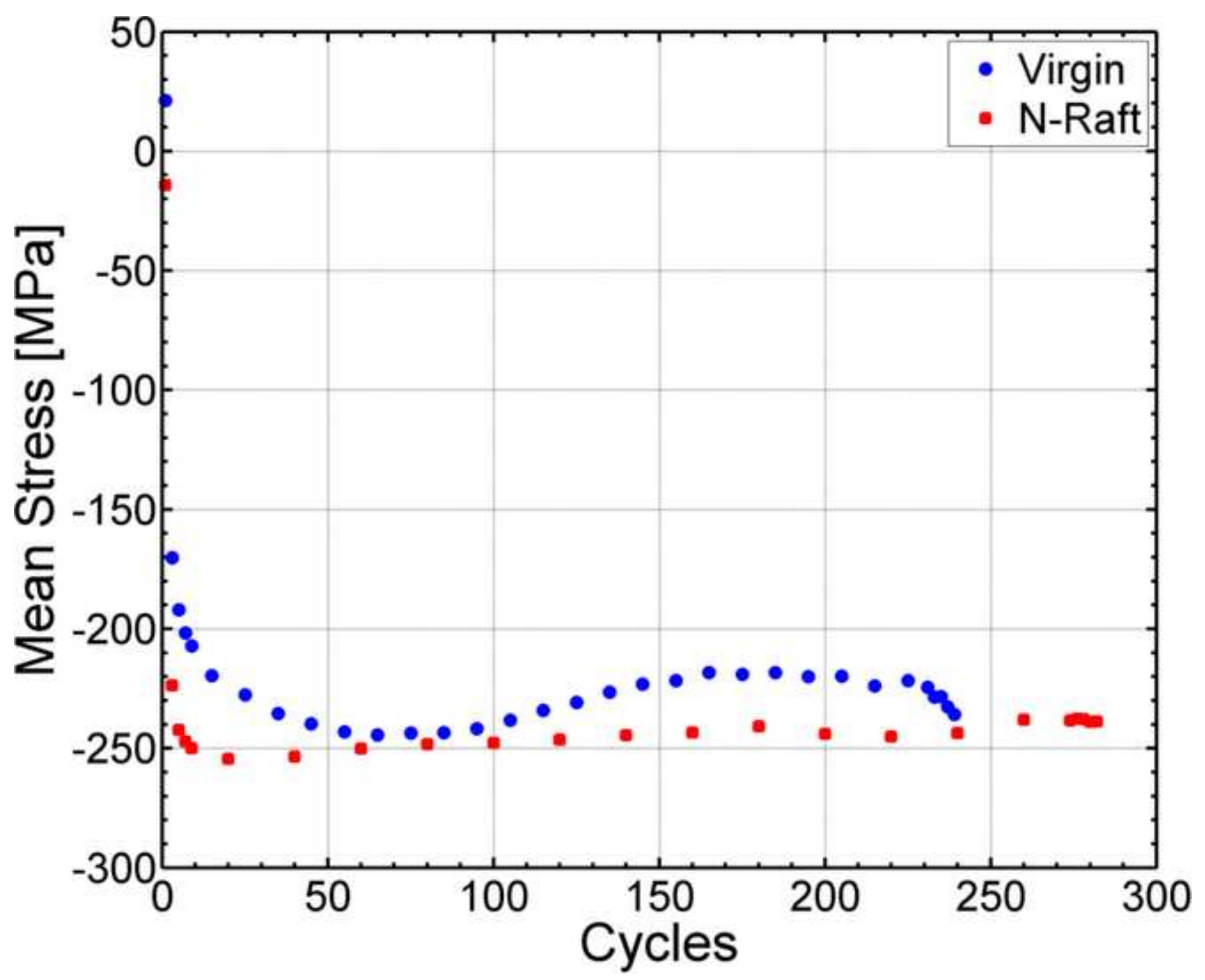



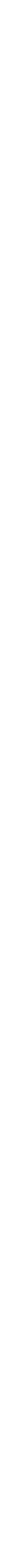


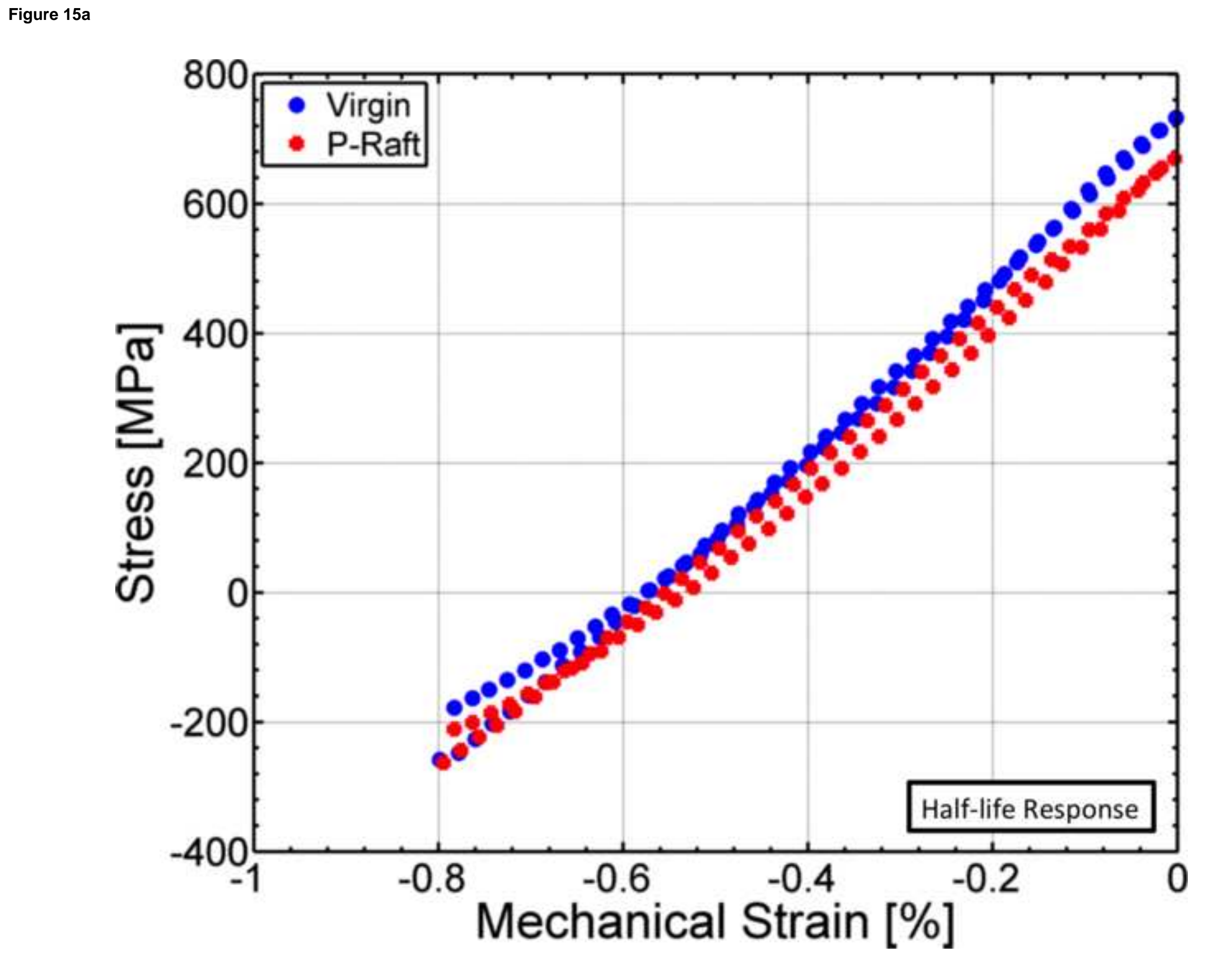

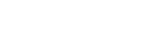

\section{Figure 15}

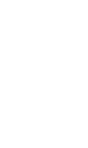

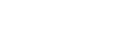

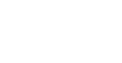




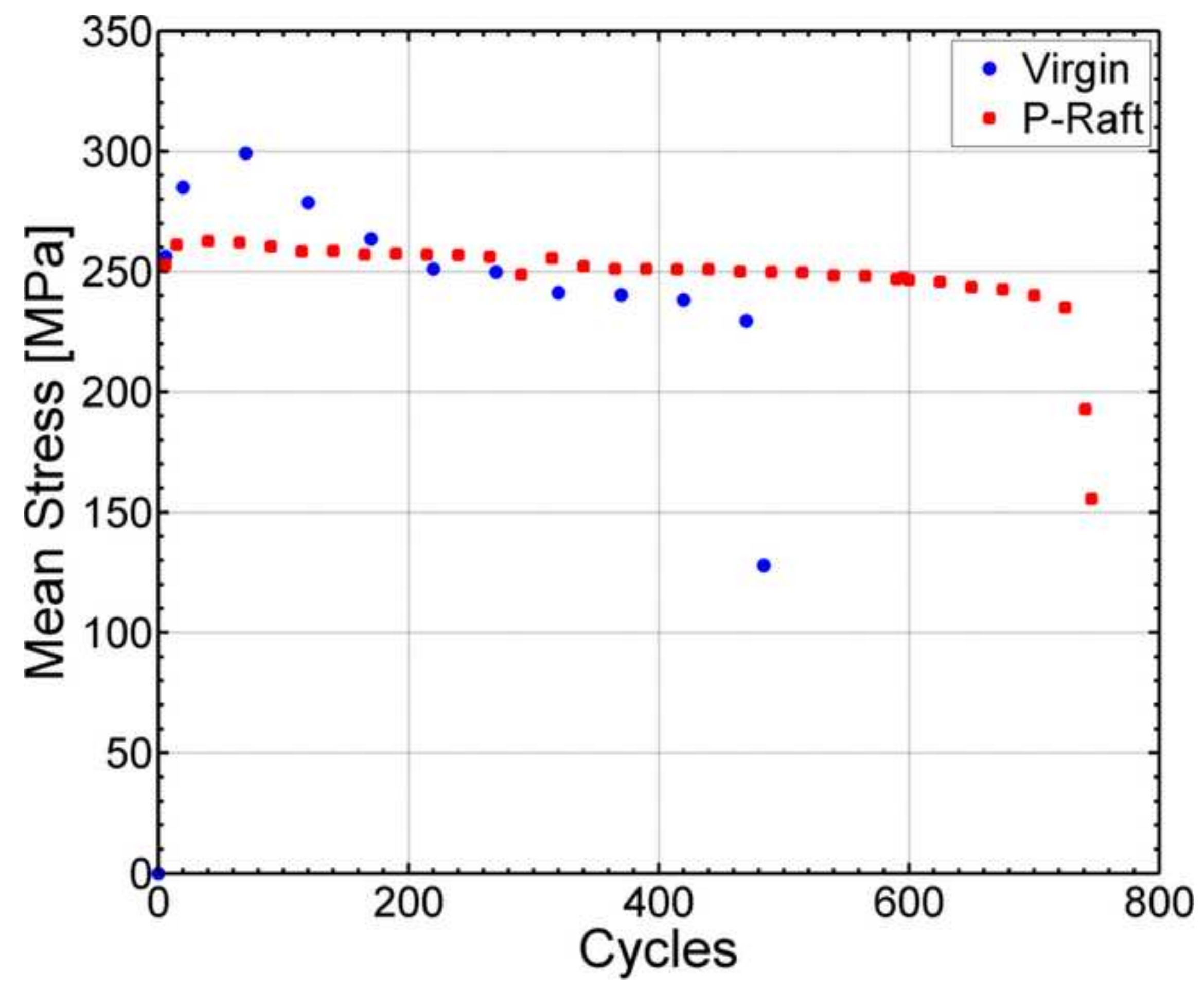


Slip Bands

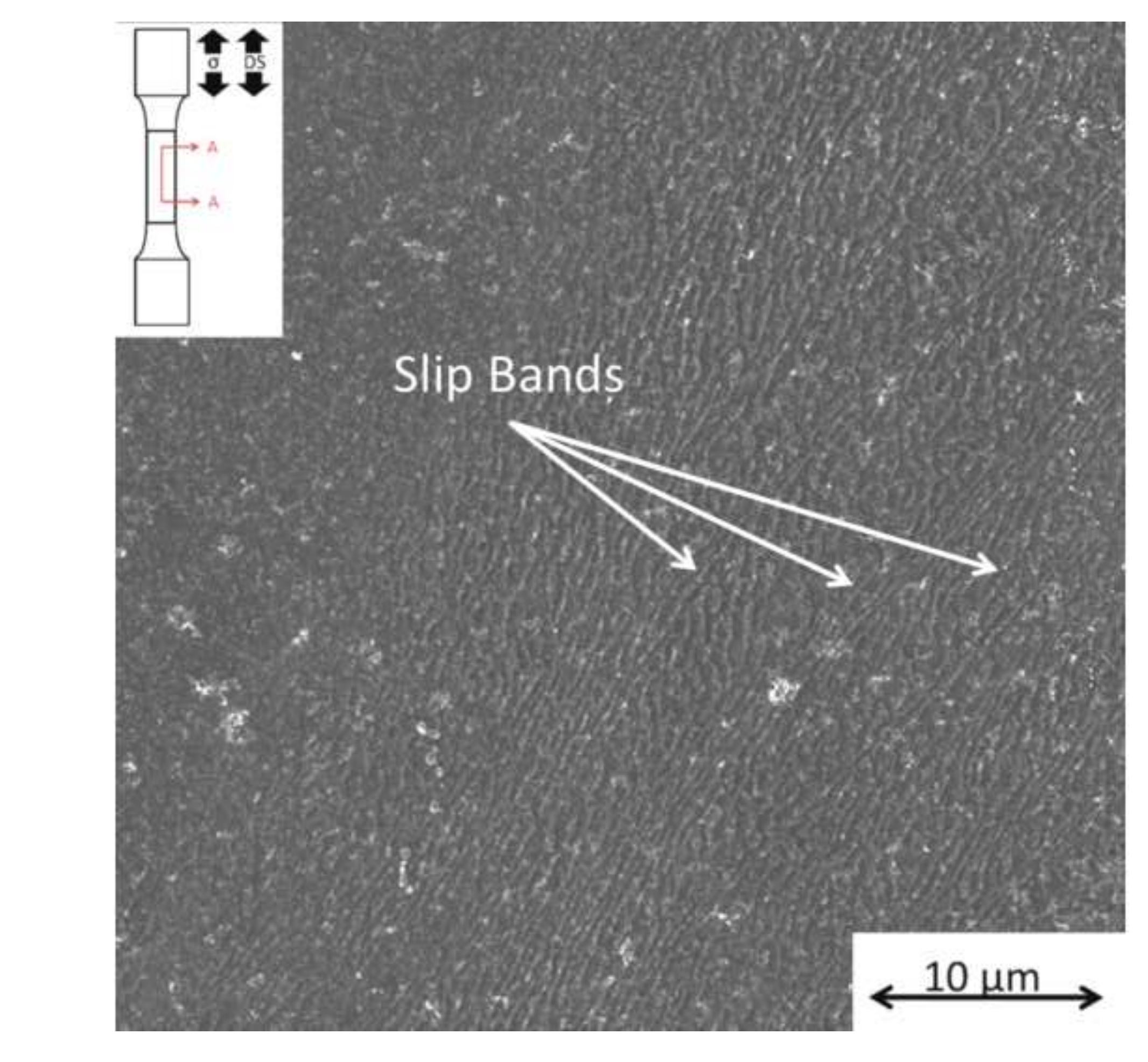

.
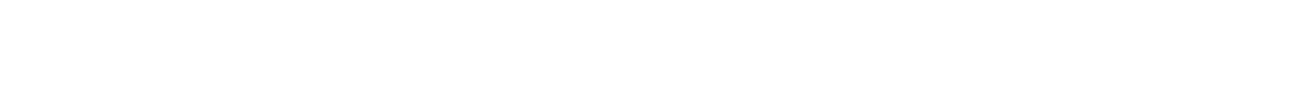


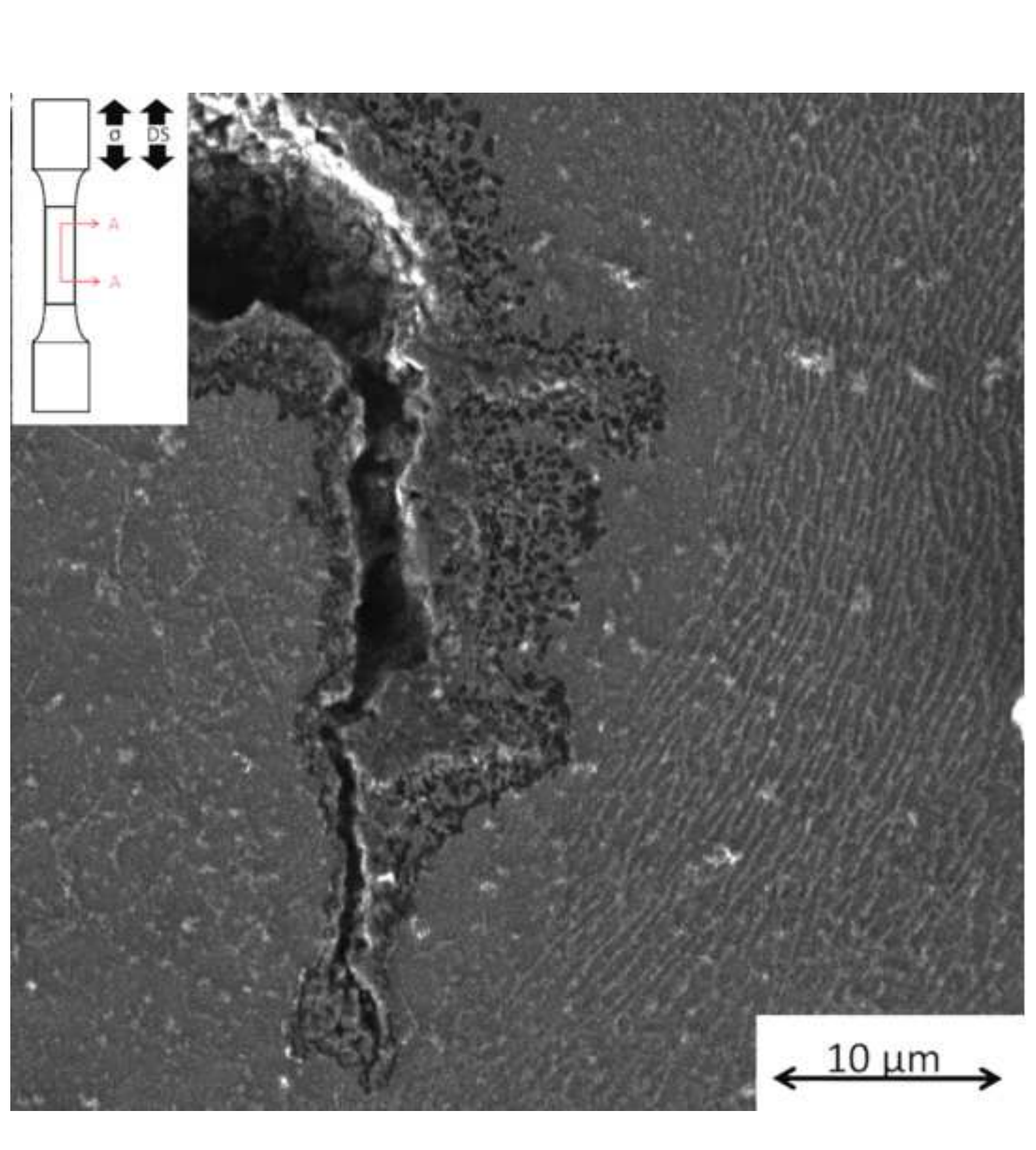

Figure 18

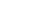

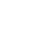

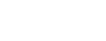
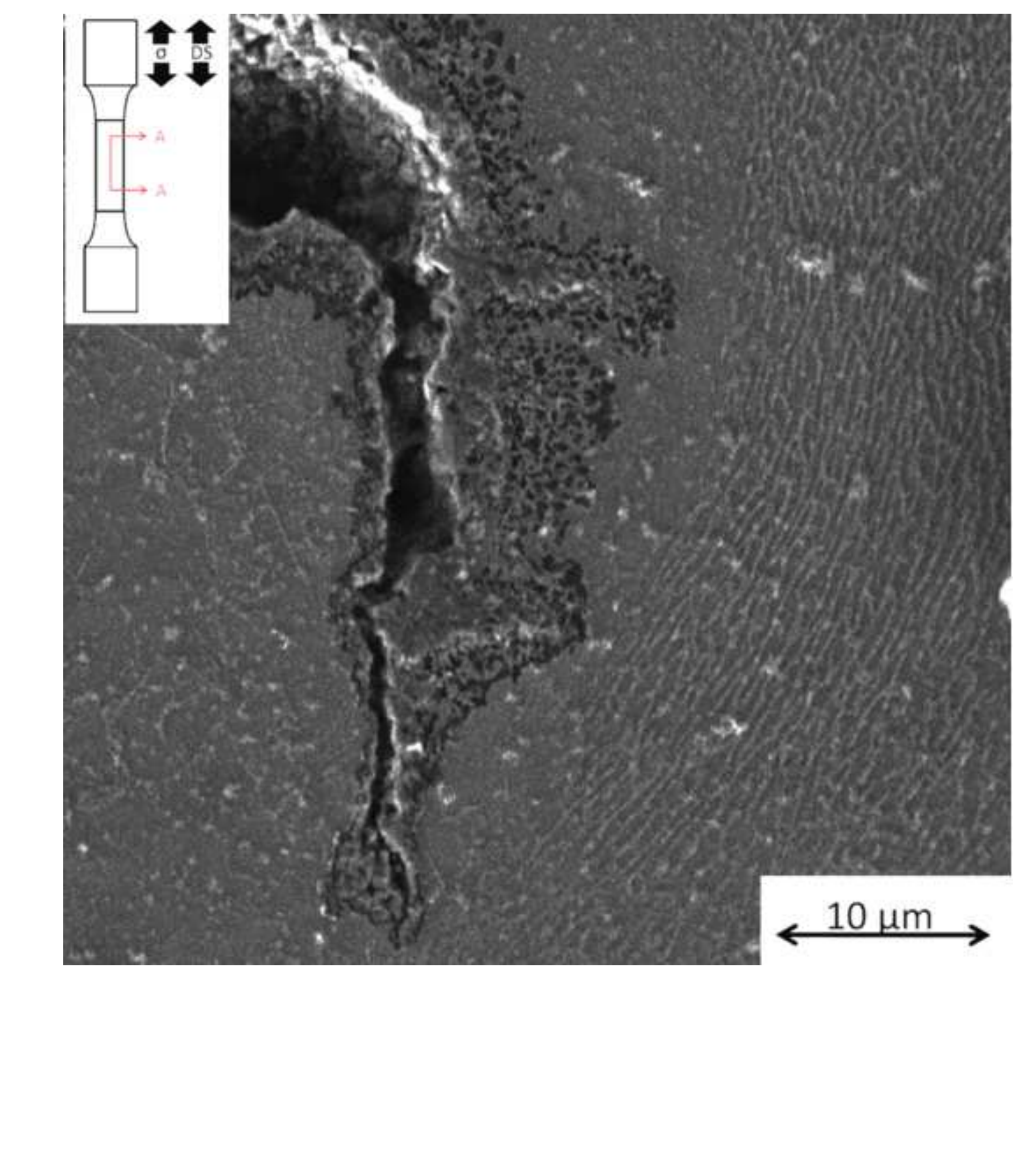


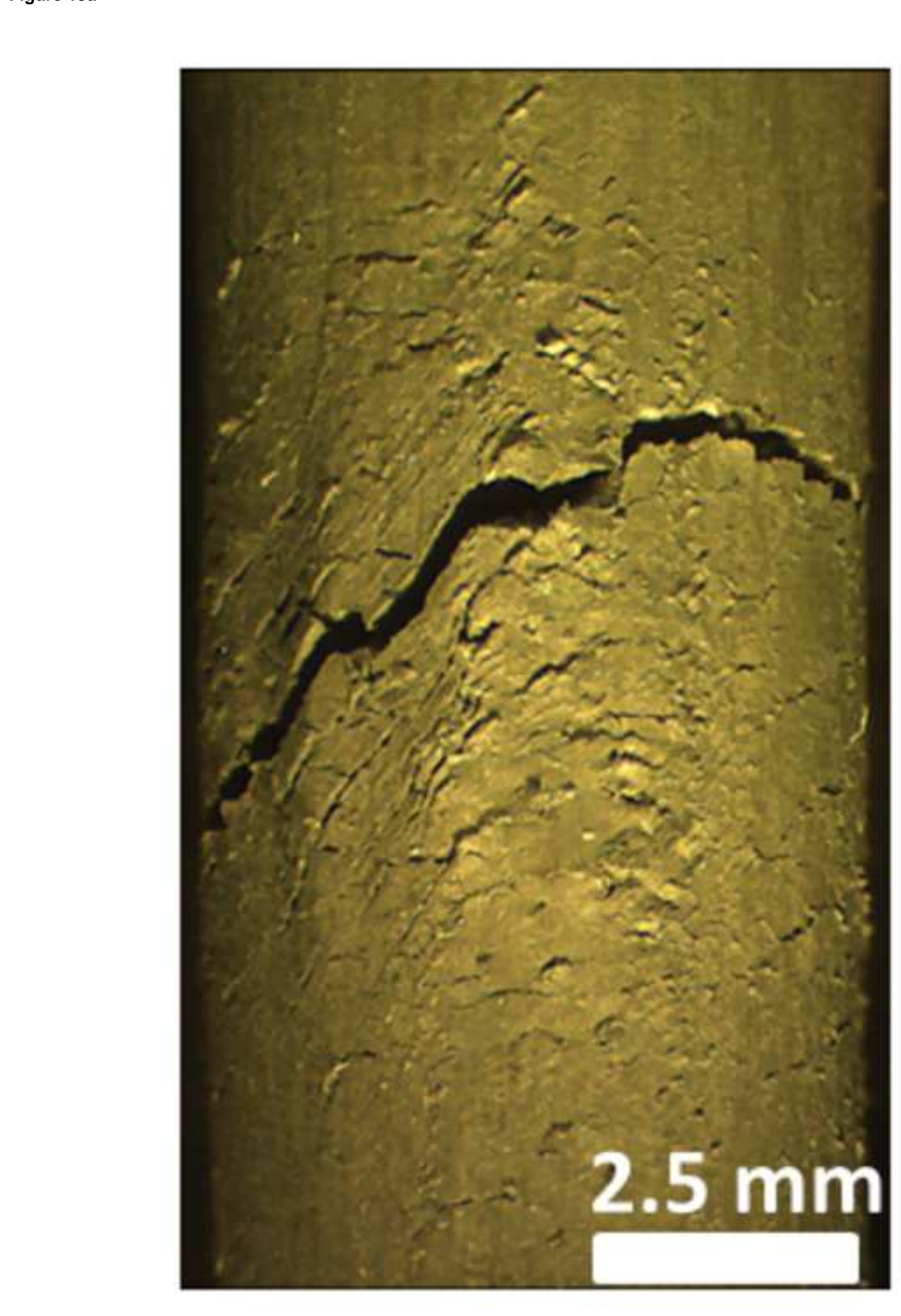

Figure $19 a$

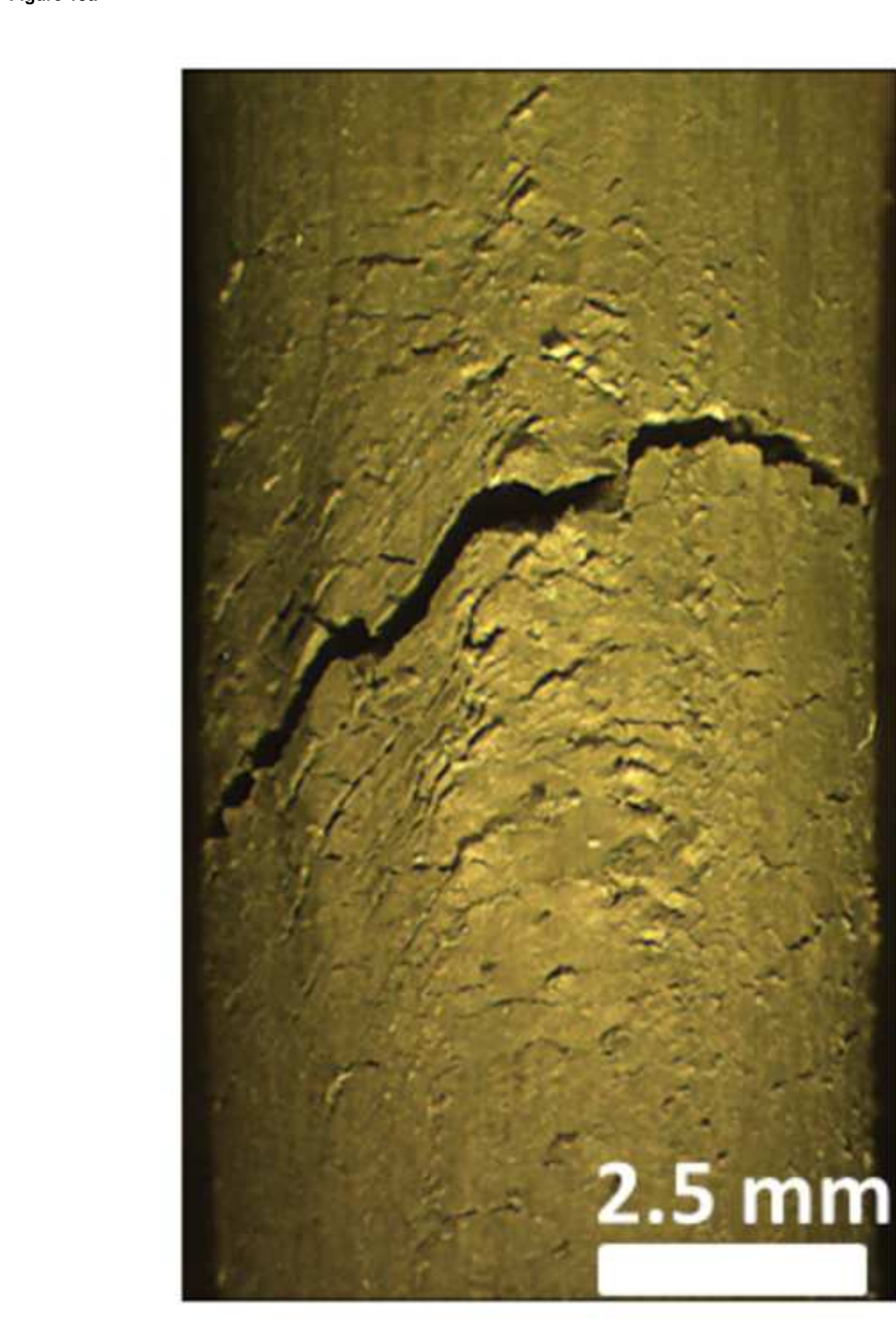

\section{a

a

.

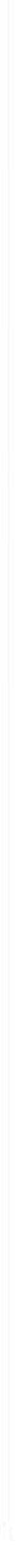
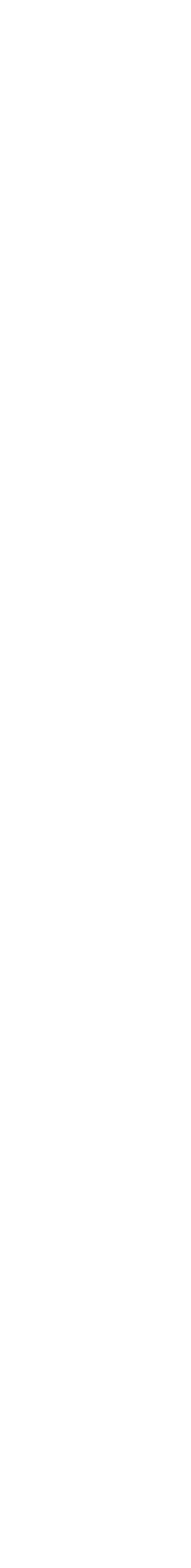


\section{Figure $19 b$}

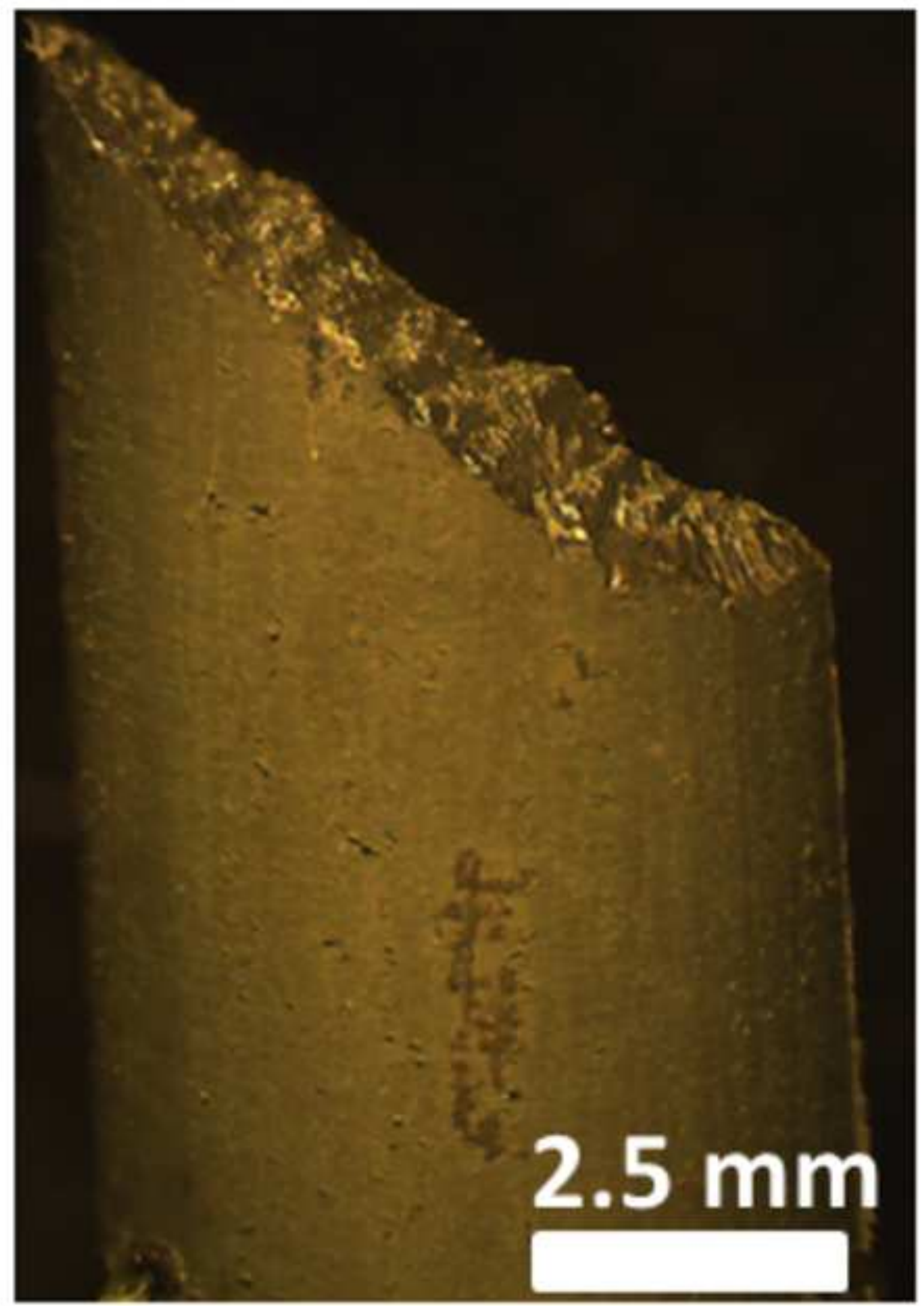


Figure $19 c$

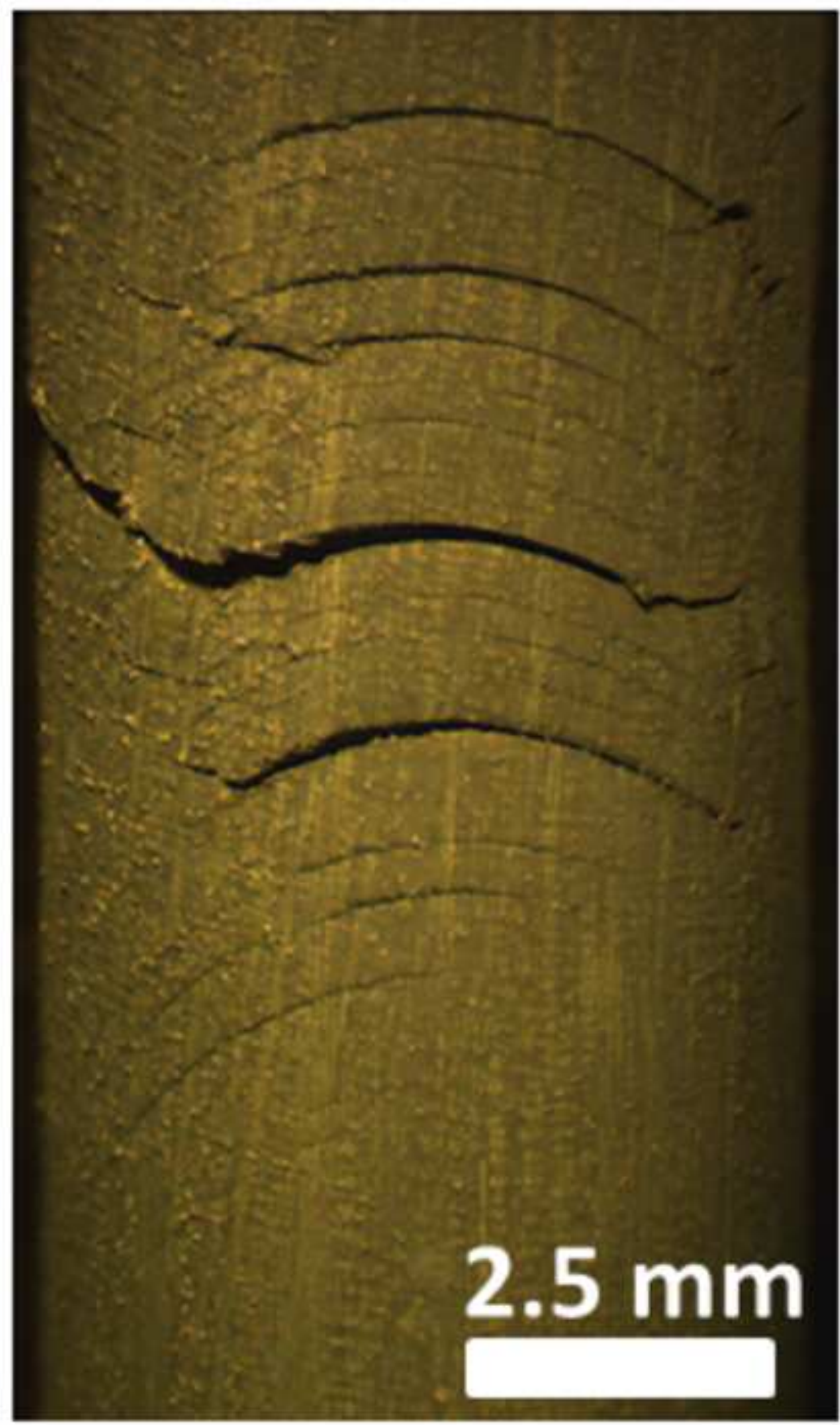




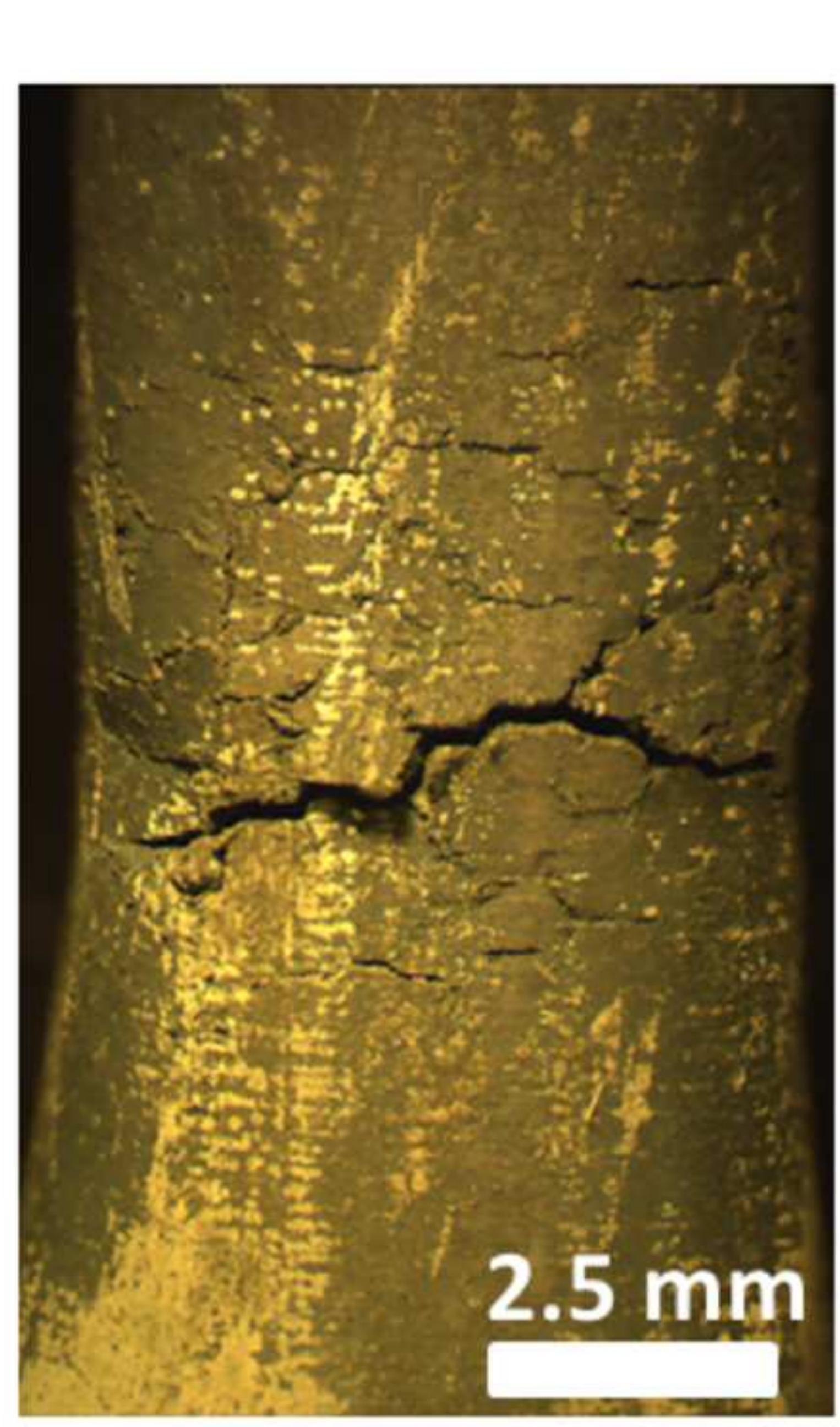

Figure 19d

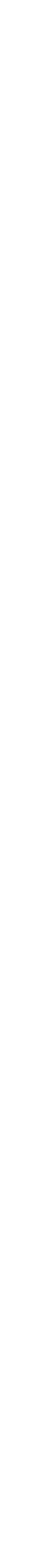

\author{
Figure 19d
}

d


Figure 20

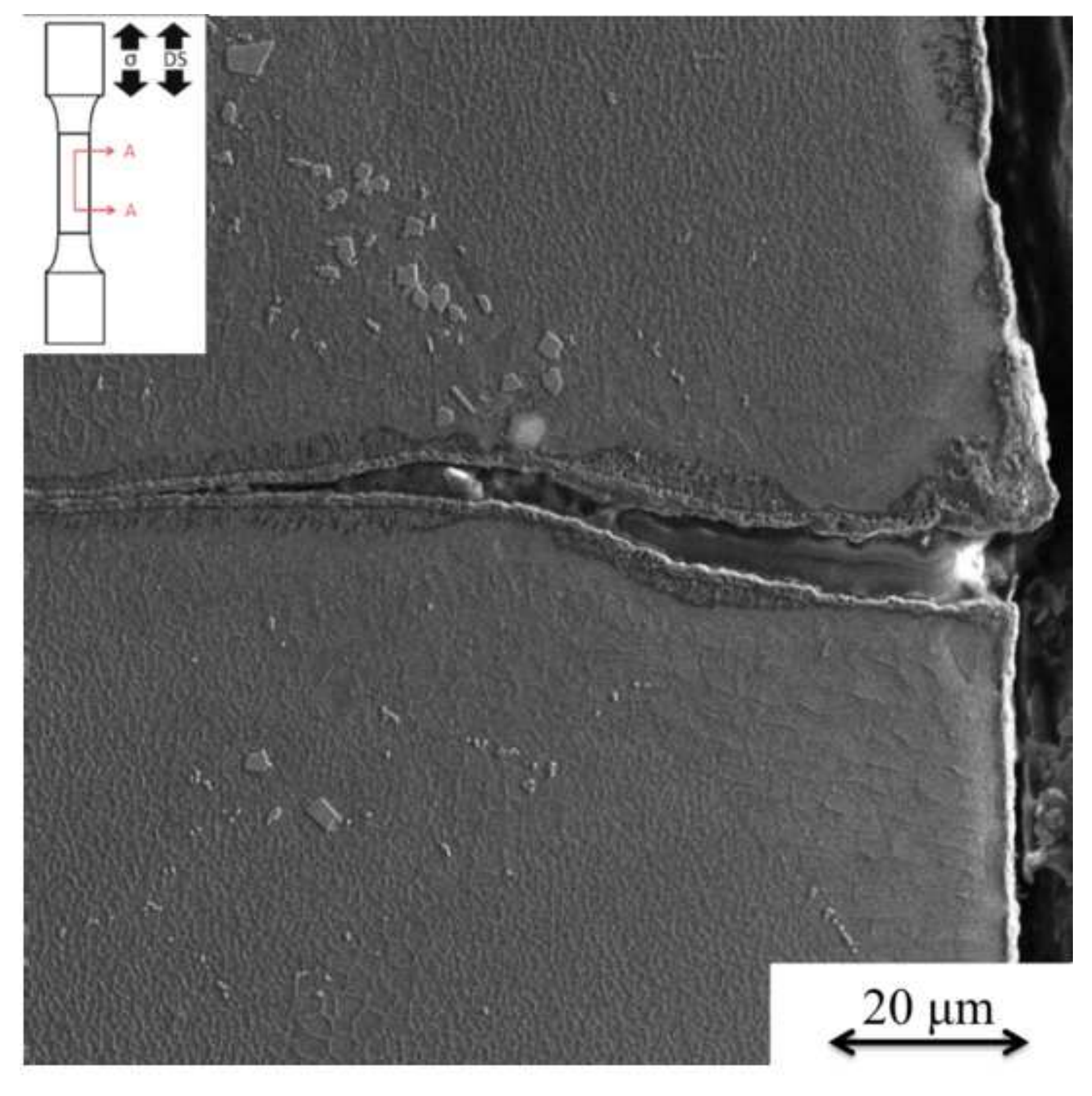

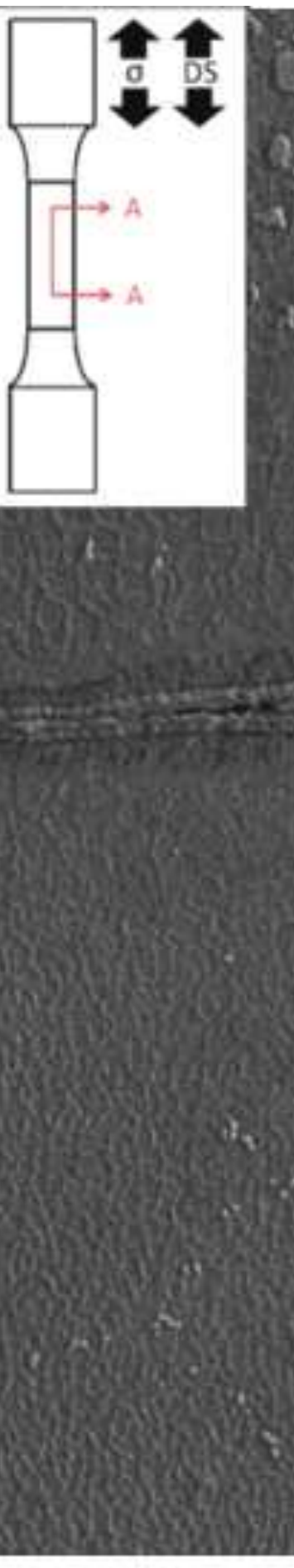
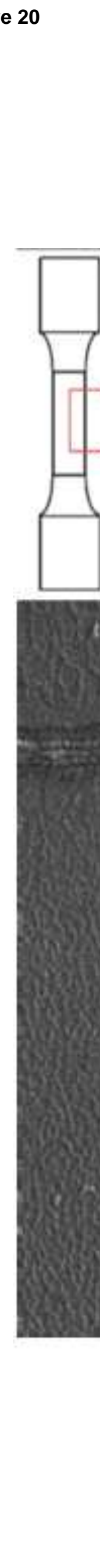

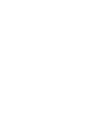

.
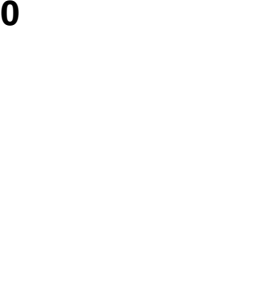